\title{
WestVirginiaUniversity
}

THE RESEARCH REPOSITORY @ WVU

Graduate Theses, Dissertations, and Problem Reports

2011

\section{Runes: Past and Present}

Elliott S. Evans

West Virginia University

Follow this and additional works at: https://researchrepository.wvu.edu/etd

\section{Recommended Citation}

Evans, Elliott S., "Runes: Past and Present" (2011). Graduate Theses, Dissertations, and Problem Reports. 723.

https://researchrepository.wvu.edu/etd/723

This Thesis is protected by copyright and/or related rights. It has been brought to you by the The Research Repository @ WVU with permission from the rights-holder(s). You are free to use this Thesis in any way that is permitted by the copyright and related rights legislation that applies to your use. For other uses you must obtain permission from the rights-holder(s) directly, unless additional rights are indicated by a Creative Commons license in the record and/ or on the work itself. This Thesis has been accepted for inclusion in WVU Graduate Theses, Dissertations, and Problem Reports collection by an authorized administrator of The Research Repository @ WVU. For more information, please contact researchrepository@mail.wvu.edu. 


\title{
Runes: Past and Present
}

\author{
Elliott S. Evans
}

\begin{abstract}
Thesis submitted to the Eberly College of Arts and Sciences at West Virginia University in partial fulfillment of the requirements for the degree of
\end{abstract}

\author{
Master of Arts \\ in \\ Foreign Languages
}
Johan C. Seynnaeve, Ph.D., Chair Cynthia S. Chalupa, Ph.D.
Deborah D. Janson, Ph.D.
Department of Foreign Languages
Morgantown, West Virginia 2011

Keywords: Runes; Fupark; Magic; Divination; Germani; Ephesia Grammata; Speech Act Theory 


\section{ABSTRACT \\ Runes: Past and Present}

Elliott S. Evans

The purpose of this study is to illustrate how the primary function of runes has changed through history. In doing so this study also begins to document the reemergence of runes especially in Ásatrú circles. Runes were historically employed for utilitarian purposes whereas they have been imbued with magical qualities in the eyes of their modern users. By using a modified version of the speech act theory, the notion of "magic" is linguistically operationalized and used to demonstrate the stark contrast between the primary purpose of historical runic texts and modern ones. 


\section{ACKNOWLEDGEMENTS}

I would like to thank my chair, Dr. Johan Seynnaeve, as well as the remaining committee members Dr. Cynthia Chalupa and Dr. Deborah Janson for their continued support and insight. It is because of their relentless dedication that this project has come to fruition, and it is my hope that this work may stand as a monument to their abilities as both instructors and mentors. I would also like to thank Dr. Patrick Conner, who nurtured in me a passion for old Germanic literature. 


\section{Table of Contents}

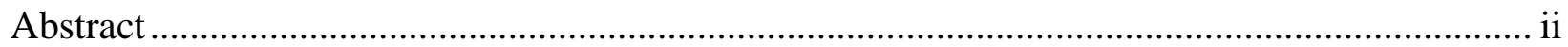

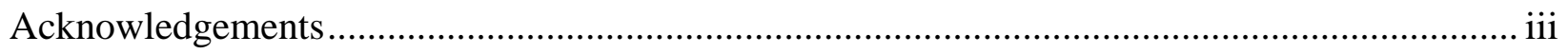

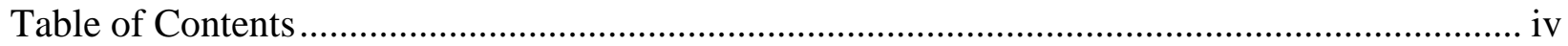

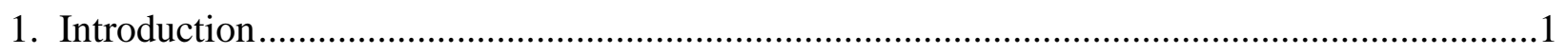

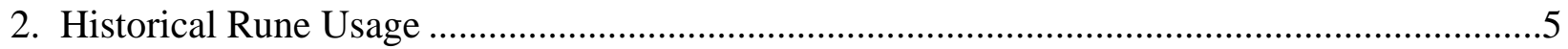

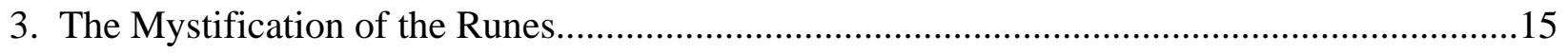

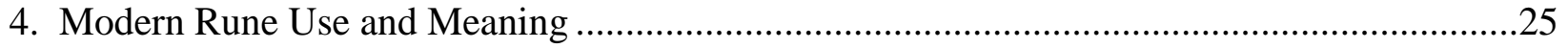

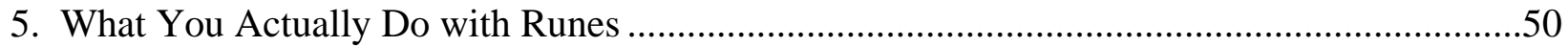

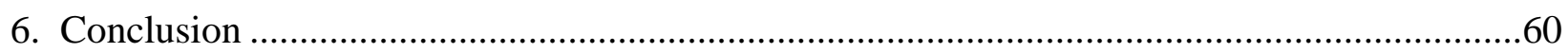

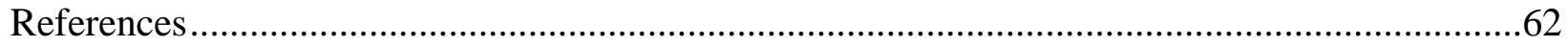

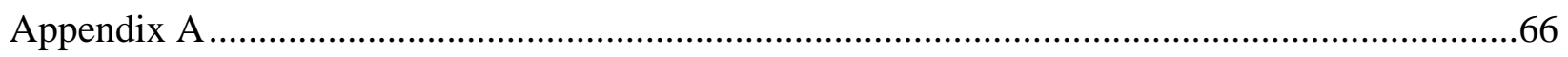

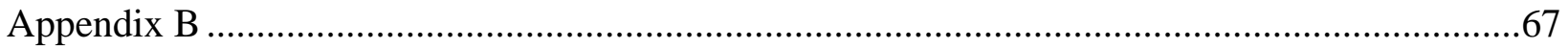




\section{Chapter 1: Introduction}

\section{Background Information and Purpose}

The words "rune" and "magic" have broad semantic connotations and are not easily defined. For this reason, these words have long intrigued Germanists and the common public alike. Since the Nordic Renaissance of the sixteenth and seventeenth centuries, when the field of runology finds its roots, many scholars have drawn a strong link between runes and Germanic pagan magic. However, an even stronger link between runes and Germanic pagan magic has been drawn by modern practitioners of Germanic paganism, which they call Ásatrú. ${ }^{1}$ The purposes of this study are to evaluate Ásatrú use of runes against the historical non-magical rune usage and to explore when and how scholars throughout history contributed to the imbuing of the runes with magic.

At the crux of this study are two terms for different runological views explained by Antonsen (2002): "romantic" and "skeptical". "Romantic" scholars assume that the Germani believed the runes to be magical, while the "skeptical" view holds that the early Germani never conceived of any rune magic. This study defends the "skeptical" view with respect to historical rune usage.

Another significant term for this study is "magic". As demonstrated in other studies, it is difficult to show the distinctions peoples of Antiquity and the Middle Ages had between magic and science, not to mention between magic and religion (Kieckhefer 1989, Bartlett 2008). Furthermore, Kieckhefer shows that medieval scholars further differentiated between demonic magic and natural magic, although these same scholars are at a loss to explicate this difference. Ultimately, for the purposes of this study, I will define "magic" as the altering or effecting of

\footnotetext{
${ }^{1}$ Although not very recent, Flowers (1981) provides a concise description of the important aspects of modern Ásatrú. The official website of the Ásatrú Folk Assembly (Ásatrú Folk Assembly 2007) provides a less thorough but more up-to-date description of the religion.
} 
reality by means which are not scientifically explainable. Although the term "scientific" is equally elusive, I will assume that if runic shapes can alter reality then this alteration is not scientifically explainable. Furthermore, the term "magic" with respect to linguistic production will be better operationalized in the fifth chapter.

In the following chapters I will show that during Antiquity and the Middle Ages the Germani considered the runes to be a utilitarian orthographic system. However, in modern times the view that Ásatrúers have of rune usage is drastically different. To shed some light on this stark discrepancy, John Austin's (1962) speech act theory will be applied to rune usage. The speech act theory examines what social effect a speaker has. According to Austin, the intent of an utterance is rarely to inform the audience; rather, a speaker more commonly accomplishes a social goal such as making promises or giving commands. Flowers (2006) already applied the speech act theory to historical rune usage. However, Flowers makes several ungrounded assumptions which cause him to make "romantic" conclusions. An approach devoid of these assumptions demonstrates that historical rune usage is in fact more in line with the "skeptical" view.

\section{Methodology}

In the second chapter I will establish that the Germani did not consider runes to be magical. This will be accomplished by examining the etymology of the word "rune", the historical act of divination, the Roman accounts of Germanic lot casting, the literacy of the Germanic peoples, and a short survey of some surviving runic inscriptions. Also in this second chapter I will argue that the word "rune" is a misnomer and did not originally apply to the fupark. 
In the third chapter I will examine two historical topics that have contributed to the "romantic" view. The first are called ephesia grammata, which are sequences of runic text that cannot be interpreted. Based on an examination of a recurring form in the ephesia grammata, non-magical suggested will be proposed. The second topic pertains to medieval literature that references runes in magical settings. By examining the context in which this literature was written, I will show that the Christian authors of this literature lacked the proper authority to make such claims about what role runes played in earlier Germanic paganism.

In the fourth chapter I will document modern rune usage. To do this I will first create a review of the literature written as guides for modern rune masters. Some major trends in this literature include meditating on the runic shapes, carving and coloring the runic shapes, and casting objects with runic shapes on them. I will then compare this published literature with responses to surveys targeted at modern Ásatrúers. Ultimately I will establish an over-arching composite view of how Ásatrúers consider runes in modern times, showing their prominent linking of runes with magic.

In the fifth chapter I will analyze historical and modern rune usage with respect to the desired effects of those who employed them. Zimmermann (2010) argues that one cannot ascertain the intent of a runic author solely by considering the archeological environments in which historical runic texts are found. However, I will show that a sobering examination of the content of a runic text considered in the cultural context to be laid out in the following chapters will reveal pertinent information about the author's desire. To this end, I will use a modified version of John Austin's speech act theory. The primary adjustment that must be made is to take into account the fact that runes are not spoken. The surviving historical instances of rune usage are all carvings or writings. Modern rune usage, however, also allows such instances as rune 
meditation. Nonetheless, this approach will shed light on what kind of intentions rune users have for both historical and modern rune usage. Indeed, modern Ásatrúers have different goals when they use runes than did the practitioners of historical Germanic paganism.

In the sixth chapter I will provide concluding remarks. Despite shortcomings due largely to limitations of time and funding, this study fills the staggering void in Germanic philology with respect to the reemergence of Ásatrú and the linguistic implications of this development. By exploring modern rune usage and comparing it to historical rune usage, I simultaneously demonstrate that the desire exists outside of academia to study older Germanic languages and cultures and that the need exists within academia to promote Germanic studies in order to provide accurate historical information for the reemergence of Ásatrú. 


\section{Chapter 2: Historical Rune Usage}

Although scholars generally agree on the translations of the old Germanic texts written in the elder fupark (see Figure 1), there is considerable disagreement about whether this writing system held magical qualities in the eyes of the Germani. The "romantic" scholars argue that the fupark possessed magical qualities, while the "skeptical" scholars argue that it was a purely orthographic script. $^{2}$ Though existing evidence demonstrates that the Germanic culture was imbued with a rich system of magic, including magical symbols for lot casting and divination, "romantic" scholars have drawn too strong a link between this magical aspect of the Germanic culture and the fupark. The purpose of this chapter is to demonstrate that the early Germani considered their fupark as a separate institution from their magic. This will be accomplished through an examination of the history of the word "rune", the act of divination itself, the Roman accounts of Germanic magic, the literacy of the Germanic peoples, and the surviving runic inscriptions.

The Word "Rune"

As discussed by Antonsen (1975, p. 39), the Modern English word "rune" harkens back to the Proto-Germanic form $r \bar{u} n-\bar{o}-n$. The early Germanic languages have reflexes of this word, which allow its meaning to be reconstructed as something secret: Gothic rüna meaning "secret", Old High German and Old Saxon rüna meaning "secret discourse", Old English rün meaning "secret, consultation", and Old Icelandic rūnar meaning "secret". Despite this etymology, there is still strong evidence that the fupark was conceived and employed for purely non-magical reasons. Several centuries of inscriptions exist before the word "rune" is used to designate members of the fupark. One of the earliest runic attestations of the word "rune" occurs on the

\footnotetext{
${ }^{2}$ Stephen Flowers, Klaus Düwel, and Ralph Elliott tend to express "romantic" views, while Elmer Antonsen, Ralph Page, Erik Moltke, and Einar Haugen are more closely aligned with the "skeptical" view.
} 
Einang stone (see Figure 2), which Flowers (1986) and Antonsen (1975) date at 350-400 CE.

The beginning of the text is missing, and Antonsen translates the text as " $(I), \ldots$ dagastiz, painted the rune" (p. 39). The word "rune" is used in the singular and therefore cannot possibly apply to the individual orthographic characters. Instead the author, whose full name has been lost, is using the word to refer to the whole inscription. For him the word "rune" retains its ProtoGermanic meaning of something secret or possibly even mysterious. The first record of the word "rune" referring to the members of the fupark, in which the text contains the word in the plural, is the Järsberg stone (see Figure 3), which Antonsen dates somewhat later at 450 CE. The existing inscriptions show clear semantic shift occurring in the fourth and fifth centuries for the word "rune". Originally, the word referred to secret or mysterious language, then to secret or mysterious language that happened to have been written in the fupark, and finally to the members of the fupark itself.

This semantic shift may have been facilitated by the existence of the Hällristningar (see Figure 5), which are rock carvings from Scandinavia containing cultic symbols and predating the earliest runic attestations (Elliott 1959). These symbols bear significant visual similarities to the fupark and were likely an influence in the designing of the fupark members' orthographic shapes. Although modern scholarship does not know how the early Germani referred to the symbols in the Hällristningar, the word "rune" may have had connotations with them. If that is the case, then illiterate Germani of the third and fourth centuries may not have been able to distinguish the cultic symbols from the fupark and may have simply called them both "runes", thus aiding the semantic shift.

Given that the fupark members were not originally known as runes, then one can explain the several documented examples of inscriptions in which the word "rune" seems to be omitted. 
A contemporary example to the Einang and Järsberg stones is the Rö stone (see Figure 4), which Flowers dates at $400 \mathrm{CE}$ and translates as "[I] Stainawari ('defender of the stones') colored (the runes)" (p. 197). Flowers himself supplies the words in parentheses as do other runologists, yet this may be linguistically inappropriate because the earlier fupark inscriptions do not call the script "runes". Instead, the verbs of such inscriptions could be treated as intransitive, i.e. "[I] Stainawari colored". The Järsberg stone is a pioneer in giving this script the title "runes", while the Rö stone displays the traditional lack of a direct object and lack of a title for the script.

It is therefore highly probable that the Germani of early Antiquity did not use the word "runes" to refer to the fupark as is the current practice. Nonetheless, this study will follow the trend of modern runology and refer to the fupark as "runes".

\section{Divination and Lot Casting}

In an attempt to separate runes from Germanic divination, it would be ideal to reference a record of Germanic divination from before the development of the runes. However, no such reference exists. Instead, this study will utilize a comparative approach of other European cultures in an attempt to reconstruct divination to a stage earlier than Antiquity. The Etruscans possessed a highly sophisticated level of prophesying and divination, including the interpretation of sheep livers, thunder, and clouds (Hayes 1963). The Celts embodied the culture most akin to that of the Germanic peoples. They also possessed a rich belief in the power of divination; a short survey of ancient Celtic religion can establish this. Monaghan (2004) explains that divination was an important duty of the druids. They observed bird flights, interpreted entrails, and interpreted how a stabbed human sacrifice fell to the ground. Davidson (1988) provides several instances of Celtic divination such as observing how a hare runs and how ash wood burns. Davidson also points out that the Celts likely had some form of lot casting like that of the 
Germanic peoples, as evidenced by the term crannchur "throw the wood".

Because the Celts, Germani, and Etruscans lived in such close physical and cultural proximity, a similar cultural phenomenon is insufficient evidence for the reconstruction of a common ritual; this cultural similarity may be due to borrowing and not due to the inheritance of an older tradition. The Greeks, however, also employed divination, which is evidenced in Apollo's replacing of Zeus as the god of divination and his subsequent establishment of the Oracle at Delphi (Hayes 1963). The Aryans of present-day Iran and India possessed a form of divination. Hopkins (1971) stresses that the nomadic Aryans who overthrew the indigenous inhabitants of the Indus Valley were much like their Indo-European relatives, with such cultural aspects as the reverence for horses and chariots, the pastoral economy, and the nomadic lifestyle. It follows that if an Indo-European belief in divination existed, then these Aryans likely held that belief as well. Perhaps the strongest Indo-European divination trait still practiced in India is embodied in the jyotisa, which is the use of astrology and astronomy to determine when important festivals are to be held (Klostermaier 2007).

It goes substantially beyond the purpose of this study to determine specifics of such an Indo-European system of divination, or whether the concept of divination is common in more primitive religions than those within the Indo-European umbrella. Nonetheless, it is significant that the lot casting employed by the Germani during Antiquity was not an exclusive characteristic of the Germanic culture; not only did other related cultures employ divination, but this concept had probably descended from a much earlier Proto-Indo-European tradition. Therefore, because divination and perhaps even lot casting almost certainly predated the Germanic fupark; it is therefore very unlikely that the Germani saw their fupark as the magical source of divination. 


\section{Roman Accounts of Germanic Divination}

There exist three significant references to Germanic divination and lot casting from Antiquity. However, none of these strongly imply the use of runes for this practice. One reference exists in chapter 10 of The Germania by Tacitus (Hanford 1970). Here Tacitus is describing the Germanic custom of lot casting. When he describes what is put on the pieces of wood for casting, he uses the Latin word notis (Winterbottom \& Ogilvie 1975, p. 42), whose plural nominative form notae is typically rendered in English as "signs" (Hanford, p. 109). This Latin word can also be translated into English as "notes, marks...characters" (Traupman 1966, p. 196) or in German as "Zeichen" (Arntz 1944, p. 236). Significant is that this Latin word is usually not translated as "letters", but rather as "notes, marks, signs". Thompson (1965) states that there is no strong evidence to support the notion that Tacitus's notae are runes and not other cultic symbols. When a literate Roman observed this Germanic process, it is unlikely that he would have construed members of the fupark as something drastically different from a Latin letter, due to the overwhelming orthographic similarities between the fupark and the Roman alphabet.

The remaining two references offer even weaker evidence for the employment of runes during Germanic divination and lot casting. Both occur in the first chapter of The Gallic War by Julius Caesar (Edwards 1939). The first occurs after one of Caesar's confrontations with Ariovistus, the king of the Germanic tribe known as the Suebii. Caesar inquires as to why Ariovistus did not attack given a good opportunity. Ariovistus's reasoning relies on "lots and divination" (p. 83). The original Latin terms sortibus and vaticinationibus (p. 82) may be translated in their nominative singular as "lot...decision by lot, prophecy" and "prophesying, prediction, soothsaying", respectively (Traupman 1996, p. 291, 326). The second reference that 
Caesar makes to this practice is a few paragraphs later when it is explained that Procillus was not killed when prisoner of the Suebii because of a decision resulting from lot casting (Edwards). Again, the Latin original yields the term sortibus. In neither case does Caesar even make reference to any symbols used in this lot casting, let alone whether these symbols may have been runic.

These three Roman accounts of Germanic divination make it difficult to posit that the Germani utilized runes in their lot casting. If lot casting indeed did employ runes, the runes themselves were relatively insignificant in the magical act. What was significant was the act of casting lots itself and not the symbols used in the act. Even if runes were used, the magic did not originate from the runes themselves but from the act of divination.

\section{Literacy of the Germani}

One crucial component of the "romantic" view of rune usage in Antiquity hinges on the notion that few Germani were literate; therefore, the presence of a writing system could easily be construed as possessing magical powers. Although caution must always be taken when grouping all the Germani together, evidence exists showing that a significant number of Germani were likely literate and had proficiencies in reading and writing Latin.

Roman cultural influence on the Germani at the beginning of the Common Era has been exhaustively documented (De Vries 1960; Thompson 1965). Thompson argues that many of the Germani living near or within the Roman borders were fluent in Latin. Additionally there were letters written from Germanic chieftains to Romans. Although these letters may have been written by Romans working for the chieftains, they were written in Latin. Significant, though, is the fact that at least some of the Germani were exposed to Latin writing. Perhaps a catalyst for the Roman influence on Germanic culture was the enlisting of Germani into the Roman army. 
De Vries proposes that service in the Roman auxiliaries was the primary means for the Germani to learn to read and write.

Although the skill to read and possibly even write Latin was not a widespread ability, the Germani were exposed to written Latin letters, and it is likely that not all Germani were completely illiterate. Because so many members of the fupark and the letters of Latin alphabet of Antiquity are nearly orthographically identical, it is absurd to assume that the Germani believed one to be purely magical and the other to have no magical qualities. The question then arises as to why the fupark, a utilitarian script comparable to the Latin alphabet, is so sparsely attested. The "romantic" argument follows that the Germani must have considered the fupark to be magical because so few texts were written in the fupark. On the other hand, as Page (1987) has pointed out, the manner in which the runes differ visually from the Latin alphabet is such that the runic shapes were designed to be carved on materials which have a grain, such as wood. The expected rich corpus of runic texts, therefore, has perished along with the wood on which it was carved. The possibility also exists that the Germani of Antiquity simply lacked the need for writing that modern society has; therefore, relatively few texts were ever carved.

\section{Runic Inscriptions}

According to the "romantic" view, the Germani, exposed to both the Latin script and their fupark, supposedly considered the Latin alphabet to be utilitarian and the runes to be magical. However, the surviving inscriptions from Antiquity paint a very different picture. It is unnecessary here to provide an exhaustive list of the runic corpus because others have excellently done just that (Arntz 1944; Düwel 1968; Antonsen 1975; Einar 1976; Moltke 1985; Flowers 1986; Page 1987). Nevertheless, relevant examples will be cited in order to show that the earliest runic inscriptions do not display magical qualities. 
Numerous runic attestations, especially those from before the middle of the fourth century, exhibit a tendency to carve a proper name on a utilitarian object. The oldest surviving engraved Germanic text is probably the Negau B Helmet (see Figure 6), which has been dated as early as $300 \mathrm{BCE}$ and as late as $90 \mathrm{BCE}$ (Reichardt 1953). Runologists dispute the meaning of this text; however, it is probably the name or the title of the helmet's owner. Although it is written in an Etruscan alphabet not in the fupark, the text is almost definitely an attestation of a Germanic language and is clearly not meant to be magical.

The oldest surviving decipherable runic inscription is most likely the spearhead from Øvre Stabu, Norway (see Figure 7). It has been dated at 150 CE (Flowers 1986), at the late second century (Düwel 1968; Antonsen 1975), at $200 \mathrm{CE}$ (Arntz 1944), and at third century (Einar 1976). This inscription contains one word, usually translated as "tester" (Flowers 1986, p. 255), which was likely the name of the spear. Another early runic inscription is the rock carving from Kårstad (see Figure 8), which Arntz (1944) dates at 250 CE and Antonsen (1975) dates as post 400 CE. Arntz and Flowers offer the translation "I, the stranger, Baier" (Arntz 1944, p. 322; Flowers 1986, p. 255), whose final word may mean something like "warrior". Regardless of exactly how the final word is translated, this inscription provides another instance of a mere name, although this is likely the name of the carver and not the name of the object.

A modest corpus exists of early inscriptions long enough to be analyzed syntactically. The oldest such inscription is likely the scabbard fitting from Thorsberg (see Figure 9), which Flowers (1986) and Antonsen (1975) date at $200 \mathrm{CE}$ and Arntz (1944) dates at 250 CE. This inscription is more difficult to decipher, although it is likely something similar to "the hereditary property of the servant of Ullr; may the Mær [sword name] not spare" (Arntz 1944, p. 318; Flowers 1986, p. 233). Antonsen offers the translation "Wolpupewaz [servant of Ullr] of 
immaculate repute" (p. 30). Neither proposed translation requires the runes to be considered magical. Another carving with sentence-like qualities is the Møjebro stone (see Figure 10), which Arntz dates at $350 \mathrm{CE}$ and translates as "Frawaradaz auf dem Hengst [wurde] erschlagen" (p. 324). Antonsen (1975) offers an English rendering of the text: "Slain on (his) steed, Frawarādaz [i.e. advisor of lords]" (p. 34). Neither of the proposed translations implies magic.

Although this survey of carvings is rather brief, the already existing runological literature well establishes that this survey exemplifies the vast majority of all inscriptions from Antiquity. These carvings exhibit quite secular ideas, such as every day actions in the case of the Møjebro stone, or they contain a single name, likely either the name of the object on which it is carved or the owner of the object. There are several examples of the so-called magic words commonly found in runic texts, such as alu, auja, and laukaz. "Skeptical" scholars have been at a loss in accounting for these stock words; however, no such argument is necessary for a "skeptical" framework. Instead, one must only realize that although these words may have been magical, the script in which they were written did not need to be. If magic words were the only surviving items written in runes then the "romantic" theory might have some merit. However, the staggering majority of carvings contain a vast collection of clearly non-magical words.

Flowers (1986) establishes the distinction in runology between analytical and integral approaches to interpretation. In an analytical approach, each rune in a text is interpreted individually, and attention is paid to the names of the individual runes. In the integral approach, on the other hand, the runes are interpreted in succession, and attention is paid to the phonemes represented by the runes. Although Flowers likely established this distinction to support the "romantic" theory, the same distinction will be used to refute the "romantic" theory. The existing runic corpus, especially from early Antiquity, must be interpreted integrally because the 
inscriptions can be read; one does not need to interpret each individual rune in a carving in isolation. There exist only a few early inscriptions that are unpronounceable and have been therefore considered magical. Flowers provides a total of 26 examples (pp. 261-263), yet no one has provided evidence supporting the fact that all inscriptions were carved by literate runemasters. Due to the fact that the fupark remained relatively unchanged in form and order across all of Northern Europe for several centuries, it seems likely that there existed a network of learned carvers. If someone other than a professional rune-master tried his or her hand at carving, the unpronounceable inscriptions would be accounted for without the assumption of magic.

\section{Discussion}

In light of the semantic shift of the word "rune", the practices of lot casting and divination, Roman accounts, the literacy of the Germanic peoples, and the surviving runic inscriptions, the "romantic" view is weakened to the point that it cannot be applied to the runic texts from Antiquity. Rather, it seems that the Germanic peoples already had a rich divination system with non-linguistic symbols and simply modeled their fupark after a Mediterranean alphabet to fulfill a newly found need for a Latin-like utilitarian script to use in their carvings. Furthermore, this completely secular employment of the script seems to have lasted until at least the fourth century, when carvings such as the Järsberg stone began calling the script "runes", a word whose etymology implies something secret. Despite the fact that the fupark received the magical name "runes", it was several centuries later before the fupark itself was even possibly considered magic within the post-Germanic culture. 


\section{Chapter 3: The Mystification of the Runes}

As will be shown in the following chapters, modern Ásatrúers often cite specific historical references to justify their belief in the magical powers of runes. However, each of these references can be explained without resorting to rune-magic by placing them in their proper contexts. It goes significantly beyond the scope of this chapter to discuss the non-magical uses of runes in the Middle Ages; furthermore, such corpora have already been well collected (Arntz 1944; Antonsen, 1975; Moltke, 1985; Flowers, 1986). Therefore, this chapter will examine not only the surviving inscriptions considered magical — that is, those texts containing ephesia grammata - but also the medieval literary references which lend runes to rune-magic. These literary references are indeed the most useful resource for examining a medieval person's perception of the runes.

\section{Texts Containing Ephesia Grammata}

The ephesia grammata are the pieces of runic text in which the runes themselves do not spell any known word; these may either be pronounceable or not. Flowers (2006) describes the ephesia grammata of the runic text carved onto the Lindholm amulet (see Figure 11) as "the specific operation itself [of rune-magic] in a higher symbolic form of discourse known to the gods" (p. 79). Such ephesia grammata occur in enough runic texts to warrant study and are perhaps the most difficult to dispense with within a "skeptical" framework. I offer the simple yet effective approach of examining some runic statistics. Flowers (1986) provides a total of 58 instances of ephesia grammata from before the Viking Age (ca. $800 \mathrm{CE}$ ), and he demonstrates that during the Viking Age itself there were significantly fewer instances. However, wanting to support the "romantic" view, Flowers does not explicitly state how many total runic texts have been discovered, which would allow the reader to judge the significance of these 58 ephesia 
grammata. Antonsen (1975) has in his corpus of runic texts before $650 \mathrm{CE}$ a total of 121 texts, while in his 2002 publication he comments that "[w]e have at best 150 texts that lend themselves to some manner of interpretation" (p. 207). Therefore, ephesia grammata occur in significantly fewer than half of the discovered texts, and most texts containing ephesia grammata also contain interpretable language. These examples of ephesia grammata were clearly an exception and not a mainstream occurrence.

With respect to the purpose of ephesia grammata, there are two significant possibilities which runologists have apparently not considered. The first is that ephesia grammata may be formulaic, meaning that the ephesia grammata are not random sequences of runes but are meaning-bearing non-words, and identical ephesia grammata may occur in more than one runic text. If this is the case, it has a serious bearing on Antonsen's (1975) distinctive feature model for the orthographic properties of the runes. Moltke (1985), Flowers (1986), and Antonsen (2002) all transcribe the third rune of the ephesia grammata of the Fyn bracteate 1(see Figure 12) as d. ${ }^{3}$ According to Antonsen's distinctive feature model, this rune is an allograph for the normal grapheme. The d-rune possesses the features [two branches, bottom] (Antonsen 1975). The deviation of the rune on the Fyn bracteate 1 is that the branches are not continuously straight and intersecting lines, one going from the top-left to bottom-right, the other going from top-right to bottom-left; instead, they are two crooked branches which never touch each other, one going from top-left to top-right, the other going from bottom-left to bottom-right. In other words, this rune resembles a $\mathbf{p}$-rune ${ }^{4}$ with an additional staff on the other side of the branches.

The recently discovered Hogganvik stone (see Figure 13) provides evidence that the Fyn bracteate 1 rune should be read as a p-rune. This stone also contains ephesia grammata, which

\footnotetext{
${ }^{3}$ The ephesia grammata of this text are transcribed by Antonsen as aadraaaliu. The "standard" $\mathbf{d}$-rune is $\mathrm{X}$, while the rune in question of the Fyn bracteates is $\bar{W}$.

${ }^{4}$ The "standard" p-rune is $\tilde{h}$.
} 
are transcribed by Knirk (2009) as aarpaa. Apart from the fourth rune being $\mathbf{p}$ and not $\mathbf{d}$, these ephesia grammata are an identical reverse of that of the Fyn bracteate 1. As stated above, the d of the bracteate is a deviant allograph with similarities to the p-rune. Therefore, the formulaic ephesia grammata of the Fyn bracteate 1 could be transcribed aapraa and not aadraa.

Proposing that the Fyn bracteate 1 exhibits a $\mathbf{p}$-rune and not a d-rune is a plausible suggestion. The p-rune of the Brezan marble column is identical to the runes in question on the Fyn bracteate 1 and on the Hogganvik stone (Antonsen 2002). A further noteworthy fact is that the p-rune of the Charnay fibula (see Figure 14) has two staffs and only the bottom crooked branch; that is, it resembles an upside-down e-rune (Arntz 1944).

The ephesia grammata of the Fyn bracteate 1 have a further relevant characteristic. Except for the vertically symmetrical runes, every odd-numbered rune in the sequence is backwards. As the rune in question appears in these ephesia grammata, it is symmetrical. It seems that the person creating this bracteate - who may not have been literate in the runesaccidentally created the rune in the regular fashion instead of backwards as dictated by the pattern, and he then attempted to fix his mistake by placing another staff on the other side of the branches. Therefore, the necessity exists for positing that the rune of the Fyn bracteate 1 is a $\mathbf{p}$.

If the Fyn bracteate 1 is indeed the same formulaic ephesia grammata as the Hogganvik stone, then Antonsen's (1975) distinctive feature model should be adjusted to compensate for the allograph of $\mathbf{p}$ and not of $\mathbf{d}$. This could possibly be done by positing a zero-value for the $\mathbf{p}$-rune with respect to [+/-two staffs]; that is, [0two staffs]. This, however, creates problems for allographs of $\mathbf{d}$ which could be interpreted as $\mathbf{p}$ and yield the text no longer meaningful, such as the Kowel spear head (see Figure 15). On the other hand, it is noteworthy that the p-rune was used rarely if ever in texts that are not ephesia grammata, and it may have likely been that the 
maker of the bracteate simply took some creative liberty in making the $\mathbf{p}$-rune in this runic formula, an act which even Antonsen (2002) believes happened frequently in general.

Given that at least some of these ephesia grammata seem to have been formulaic, the wide range of possibilities arises regarding their purposes. Only speculations can be offered, but non-magical speculations are just as feasible as the magical ones already proposed. For example, these formulaic ephesia grammata could be something akin to modern-day signatures, company logos, or nicknames. Without further information about the contexts of these runic texts or about their authors, nothing definitive can be stated. However, the need no longer exists to assume these ephesia grammata are magical.

The second possibility pertains to why ephesia grammata may have been carved. Page (1987) furthers a relevant argument by Derolez dealing with the number of surviving inscriptions. If there were only ten rune carvers at any given time in the whole Germanic land, and if they each carved only ten carvings per year, then there should have been approximately 40,000 inscriptions from $100 \mathrm{CE}$ to $500 \mathrm{CE}$. However, a number closer to one hundred survive from this early period. Therefore, Page believes that the overwhelming majority of runic texts have not survived, as they were likely carved on perishable materials such as bone and wood. Noting a similar situation for the number of surviving Anglo-Saxon runic texts, Page (2006) comments that " $[t]$ he inevitable clear and general conclusion to be drawn is that from the surviving material it is impossible to draw any clear and general conclusions" and that "from the surviving material it is impossible to disprove any general conclusions that others have drawn" (p. 272).

However, the apparent lack of surviving material can be interpreted differently. I posit the possibility that there were relatively few literate rune carvers. Therefore, it may well have 
been the case that a Germanus desiring to have a runic inscription made could not find a rune carver to employ, and he simply made his or her own best effort. As shown in the previous chapter, there is strong evidence that the early Germani were at the very least acquainted with Latin writing; however, there exists no method of determining exactly how literate these early Germani were. If there existed the gamut of literacy from completely illiterate to completely literate, then the varying degrees of ephesia grammata can be accounted for, from the completely illegible Yarmouth stone (see Figure 16) to the readable but not interpretable Krogsta stone (see Figure 17).

\section{Literary References to Runes}

There exist a handful of medieval literary references to rune usage exemplifying runemagic. Because these references are eagerly cited by modern Ásatrúers and "romantic" runologists alike, these references will be considered within their contexts in order to critically evaluate whether or not they support the theory of rune-magic. These references occur on the British Isles and in Scandinavia. Despite the common Germanic heritage, the German counterpart of the Scandinavian sagas, the Nibelungenlied, is completely devoid of rune-magic, showing that a significant portion of the Christianized descendants of the Germani made no literary references at all to the magical powers of runes.

English. Of the surviving runic texts of England, perhaps the one which most lends itself to rune-magic is the Old English rune poem. This poem offers not only the names of each rune of the Old English fuporc, ${ }^{5}$ but also a stanza for each rune explaining the meaning of its name in traditional Germanic verse. For the imaginative mind such a poem can conjure up ideas of the

\footnotetext{
${ }^{5}$ Because of certain sound changes that occurred in prehistoric Old English, the vowel quality of the fourth rune of the fupark changed. The Anglo-Saxons also preferred $c$ over $k$ when using the Latin script. Therefore, the AngloSaxon runes are known as the fuporc.
} 
runes themselves possessing the qualities expressed in the poem, and it is from there but a small step to posit that the runes may affect reality in the same way that the objects they represent do. However, these "romantic" views are completely devoid of context. Based on linguistic features, Halsall (1981) demonstrates that the Old English rune poem was likely not recorded any earlier than the eighth century, which is significantly after the conversion of the AngloSaxons to Christianity. Because the poem was written with pen and paper, it was almost certainly written by a Christian monk and not a heathen. Conner (2008) argues that the runic inscription on the Ruthwell cross was likely made later than the ninth century; if this is so, then the Anglo-Saxons possessed either a continued interest in the Germanic runes or an antiquarian interest in the pre-Christian times. Because of the 46 manuscripts cited by Conner to contain runes as well as the runic inscriptions on Christian items such as the Ruthwell cross, it seems only logical that the Anglo-Saxon interest in runes was not at all heathen. In a remark to the Sermon of the Wolf's complaint about heathen abuses, Marsden (2004, p. 217) states that "there were specific penalties in Anglo-Saxon law for sacrifice, divination and any kind of idolworship". The fact that the use of runes in England significantly outlasted Germanic magic suggests that Anglo-Saxons did not consider runes to be magical. It seems very unlikely that a Christian monk would have worked to conserve heathen magic by preserving an illegal heathen text.

Halsall (1981) instead argues that the rune poem and perhaps even the rune names themselves were nothing more than pneumonic devices to help students learn the sounds and order of the fuporc. This proposal is extremely likely in the context of a society that outlawed heathen magic but had more than a passing interest in the runic script. As shown by Conner (2008), this Anglo-Saxon interest in the runic script lasted until at least the Norman Conquest. 
Furthermore, this runic interest could not have been fueled by an interest in heathen ways; Conner argues that it was the church itself that propagated the Anglo-Saxon fuporc.

Scandinavian. There exist two rune poems from Scandinavia; one from Norway and one from Iceland (Halsall 1981). Both possess the same basic characteristics of the Old English rune poem, and both are subject to the same critical approach. Furthermore, one can reach the same conclusion for them as for the Old English rune poem: they were likely written down by Christian monks after the establishment of Christianity as literature for those interested in the runic script and not as a means of sustaining heathen magic. Because Scandinavia offers medieval literary references which support the alleged rune-magic more than any of the three surviving runic poems, the Scandinavian rune poems shall receive no further specific attention.

According to the Hávamál, the Norse god Odin sacrifices himself by being hanged from the great world tree so that he can gain knowledge. Shortly before he falls from the tree, he spies the runes and picks them up. The following stanzas describe spells that Odin has learned, and they make several references to runes (Terry 1990). However, there exists no evidence that either the runes Odin found or the runes in the spells are the members of the fupark. As shown by Elliott (1959), the Germanic peoples did possess a non-fupark cultic script typically referred to as Hällristningar, so-called because they are most commonly found carved on large stone faces. It is entirely possible that the Odin of the Hávamál discovered this cultic script and that the references to runes in the spells use the word "rune" to mean a magical utterance and not a member of the fupark. In reference to The Second Lay of Helgi Hunding's Bane, Bellows (2007) explains that "[t]he word 'rune' had the meaning of 'magic' or 'mystery' long before it was applied to the signs or characters with which it was later identified" (p.63). 
In the Greenland Lay of Atli, Gudrun wants to warn her relatives of Atli's cruel intention without alerting Atli; therefore, she carves a message coded in runes. Vingi, one of Atli's warriors, realizes what is going on and decides to alter the runic message before delivering it to Gudrun's relatives. When Kostbera attempts to decipher the message, she is unable to interpret the runes correctly (Terry 1990). In this lay some orthographic system is used as a means of coding a message. Although there is no evidence that this orthographic system is the fupark, magic would not necessarily have to come into play if it were. Using a script as a code does not imply that the users of the script consider the script to be magical. No character in this lay considers Gudrun's usage of the runes as a code as being able to alter reality in any way at all. According to the Saga of the Volsungs, the episode in which Gudrun warns her relatives transpires slightly differently. Here she carves an encoded, runic message on a ring to warn her relatives, but Vingi carves over it to make it appear as though Gudrun were urging her relatives to come. In this saga Kostbera realizes that the runes have been altered and suspects Gudrun's true intention (Byock 1990). Despite the specific differences, the same critical approach may be taken here as with the Greenland Lay of Atli. The runes are used as means of encoding a message; however, there is nothing to support the notion that any characters in the saga considered the runes to possess any sort of magic whatsoever.

According to the Lay of Sigrdrifa, the valkyrie Sigrdrifa teaches the protagonist Sigurd several magical spells, which she calls runes. These spells include limb-runes, ale-runes, and mind-runes (Terry 1990). However, there is again no evidence that these runes are members of the fupark. The fact that the etymological meaning of the word "rune" implies something like a mystery or whispering is significant here. It is entirely possible that the word "rune" had also retained its original meaning along with its newer meaning referring to the fupark at the time that 
these lays were recorded. Furthermore, the fact that the rune poems have no runes with meanings even similar to limb, ale, or mind deals a devastating blow to the notion that the runes in this lay are the members of the fupark.

Likely recorded by Snorri Sturluson in the second quarter of the thirteenth century, Egil's Saga offers what seem to be very clear instances of rune-magic. In the seventy-third chapter, Egil visits a farmer named Thorfinn. Thorfinn's daughter Helga is sick, and Egil finds out that someone has tried to cure her by carving runes on a whale bone. Egil examines the bone and discovers that the runes were not carved correctly. After explaining that carving runes incorrectly can cause more harm than good, Egil destroys the bone and carves new runes. Helga soon recovers (Hreinsson 1997). Two aforementioned arguments need to be made here. First, the saga does not provide the reader with a description of either carving; it is entirely possible that the symbols are not members of the fupark. On the other hand, even if they were, it is incredibly important to bear in mind that this saga was recorded in Iceland after the establishment of Christianity. Unlike the English references, this reference to runes does involve magic; however, it was likely made in an antiquarian context where the possibility of skewing particular ideas for the sake of imaginative interest certainly existed.

\section{Discussion}

A cursory overview of runic material dating after the first few centuries of rune usage weakly supports the "romantic view", based on ephesia grammata and certain medieval literary references. The existence of ephesia grammata implies that some Germani considered certain unreadable runic inscriptions to have some function other than as a simple writing system. The literature from the Middle Ages also suggests that in a few instances there were some descendants of the Germani who considered runes to be inherently magic. However, when these 
medieval authors were referring to "runes", they were most likely not referring to members of the fupark but instead to some other Germanic spells. Furthermore, most of these references were made by Christian writers who had an antiquarian interest in aspects of the older Germanic culture. Moreover, although current scholarship has not reached a consensus as to the purpose of the ephesia grammata, immediately resorting to rune-magic is neither warranted nor necessary. This medieval confusion of runes with pre-Christian Germanic magic was not the mainstream view of those Germanic heathens who actually created the oldest surviving texts written in the fupark. 


\section{Chapter 4: Modern Rune Use and Meaning}

In the previous chapters I established how the Germani of history viewed the fupark. During Antiquity there is no evidence that the Germanic peoples considered their writing system magical. Although during the Middle Ages some literary works refer to the magical quality of runes, these references either fail to show explicitly that the symbols referred to as "runes" are members of the fupark or were composed by people who lacked important knowledge about earlier Germanic pagan beliefs. The purpose of this chapter is to document modern Ásatrú rune usage and demonstrate how the misconceptions of the medieval scribes continue in an exaggerated fashion among modern Ásatrúers. This will be done by examining published Ásatrú literature and individual survey responses and by synthesizing the modern meanings of individual runes.

The term "modern", however, poses an initial difficulty with respect to rune usage. One the one hand, rune usage is attested shortly after the Middle Ages. Thorsson (1984) argues that runes were used in Scandinavia after the Renaissance as a form of code for the military. Arntz (1944) and Plowright (2006) show that in Scandinavia runes were used in various contexts such as on calendars as late as the eighteenth century. However, instances as early as these are unbroken continuations of historical rune usage stemming from the Middle Ages. On the other hand, rune usage as part of an organized neo-religion appears fairly late. Kaplan (1996) describes modern Ásatrú and its Rune Guild as having their roots as late as the 1960's. Therefore, I posit the ground-breaking work of Guido von List, published in 1908, as the beginning of the modern rune usage (Flowers 1988).

\section{Guido von List}

Before examining the content of List's work, the literary context in which it was written 
should be illuminated. It goes beyond the scope of this study to provide a review of German literature leading up to List's work. However, two authors deserve particular mention because of how their work at times stands in opposition to List's while at others can be seen as the forerunner for List's. Very prolific writers, Jacob and Wilhelm Grimm have undoubtedly shaped Germanic studies more than any other authors. Their writings, however, do not reach a consensus concerning the topic of runes. Jacob Grimm, in his monumental work concerning German(ic $)^{6}$ mythology, provides a thorough discussion of runes as magical spells but makes no mention of the fupark script (Stallybrass 1966). Wilhelm Grimm, on the other hand, devoted an entire book to German(ic) runes; however, no mention is made of the magical spells of the Middle Ages (Grimm 1821). In order to reconcile the magical ideas portrayed in the etymology of the word "rune", Wilhelm Grimm posits that writing must have been rare among the Germani and subsequently thought of as mysterious. These two Romantic ${ }^{7}$ scholars show a realization that the term "rune" could refer to either a magical aspect of Germanic paganism or a member of the fupark, although these two definitions of the word "rune" are kept separate in their works. Later scholars, such as List and Flowers, allow these two notions to intermingle to an even greater degree than was done by medieval scribes.

List's work, Das Geheimnis der Runen, tends to portray runes as being esoteric, mystical, magical, and culturally significant for Germani of both history and his time. According to Flowers (1988) List's insight into the runes came when his eyes were bandaged for several months after cataract surgery, showing that List's work is grounded on his own esoteric epiphanies instead of on historical research. Generally List argues that the Germani were the

\footnotetext{
${ }^{6}$ His work, titled Deutsche Mythology, was written before there was a unified Germany. Therefore, translating Deutsch as either "German" or "Germanic" can have deep political ramifications, similar to the debate reviewed in Antonsen (1980). This political debate is not relevant to this study, and I will translate it as both, i.e. "German(ic)". ${ }^{7}$ Here I mean Romantic in the sense of the artistic movement beginning the $18^{\text {th }}$ century, not "romantic" in the sense of believing runes to have magical qualities.
} 
superior and natural successor of the Indo-Europeans, whom he calls "Aryan", and that the Latin and Greek offshoots present less perfect portrayals of the ideal Aryan life. Essential to this Aryan and subsequent Germanic lifestyles were the presence of runic shapes and the ideas associated with them. Furthermore, List considers the runes to be inherent in the Volksgeist of the speakers of modern Germanic languages. He also comments at length as to the meaning of each member of his Armanen fupark, which is in his opinion the original runic row, and how these meanings have evolved in his society. Often, however, List's claims lack academic validity, as even admitted by his admiring translator Flowers. One such implausible claim is that the Visigoths named the region of Gibraltar after the meaning of the g-rune. Based on the name of Gibraltar, List furthers this argument by claiming that the Visigoths dedicated this region to the god Odin.

Although List rashly and romantically justified his arguments, and no academic runological scholar seriously subscribes to his theories, his work does show an early and significant step in modern times to romanticize the fupark and its meanings. Even a century after List's publication, modern Ásatrúers have an understanding of runes based not exclusively on early Germanic history but also on List's writings. Both published Ásatrú literature explaining rune usage and responses to the surveys show strong similarities to List's work.

\section{Modern Rune Usage}

Unlike historical runic usage, there is no corpus documenting modern rune usage. In order to create one for analysis in this study, I will examine both published Ásatrú literature and confidential survey ${ }^{8}$ responses targeted at soliciting characteristics of rune usage performed by practicing Ásatrúers. One of the most productive authors examined in this published literature is Flowers, who writes under the alias Thorsson when writing for Ásatrú circles. Other authors,

\footnotetext{
${ }^{8}$ A copy of the survey is included in Appendix A.
} 
such as Blum, Fitch, and Plowright, have also contributed significantly to this collection of modern Ásatrú literature. The survey was performed via e-mail and was sent to all eighteen email addresses available on the Asatru Folk Assembly's website (Asatru Folk Assembly 2007). Four recipients of the survey responded. This number, although statistically low, is sufficient here because this study is qualitative and not quantitative. The purpose of the surveys is to illustrate how the runic beliefs of the common Ásatrú practitioners either differ or resemble those of the authors of published Ásatrú literature.

Upon an examination of the published literature and the surveys, certain trends emerge. Modern rune usage can be roughly classified into three broad categories, listed here from most mundane to most spiritual: carving, divination, and meditating and hallowing. For each of these categories I will review pertinent information from the published literature and the surveys in order to demonstrate what purposes runes serve in modern Ásatrú. Following this I will synthesize the meanings for each of the members of the fupark based on the published literature in order to illustrate that the individual runes themselves have acquired significantly deeper meanings than they had during Antiquity or the Middle Ages. Finally, I will produce a collective representation of modern rune usage for speech act analysis in the following chapter.

Carving on items. The carving of runes onto various items is a common means of using runes in modern times. Nearly all of the published literature as well as the survey responses point to rune carving as the most basic way of working with runes. Although not all runic carvings are necessarily construed as magical in the eyes of the modern Ásatrúers, the fact that they employ the runic script as opposed to a Latin-based script in their carvings demonstrates their belief in the quality of the carving ritual as well as the importance of the runic script itself. 
Fitch (1990) offers a section on runes and runic rites. Fitch's runic framework is not extremely structured with respect to such things as what materials are required for a runic ritual and even what does and does not constitute a rune. However, after providing the reader with an interpretation of the Old English fuporc as well as several Norse cultic symbols, Fitch does offer a step-by-step walkthrough for a rune-talisman rite. Stressed by Fitch are the oral utterances which are to be performed during the carving and mystifying of the talisman. These utterances serve the purposes of invocating the gods, praising the gods, and offering compensation to the gods if they allow the rune-user's magic to be successful. Finally, Fitch urges the rune-user to keep the talisman on his or her person at all times. For Fitch the carved runes are a tool for communication with the divine.

Thorsson (1994) describes the act of rune carving and states that "[a]s far as ritual is concerned, the simplest form is that of rune-carving itself' (p. 29). For Thorsson, however, carving runes inherently taps into a greater religious doctrine which he sets out to describe. In this book he stresses the abstract notions of the runes themselves and much less the actual process of carving runes. For example, he argues that the runes are a map of not only the entire cosmos but also the human psyche. Furthermore, he states that the runes are a mysterious transpersonal system that was not created by any single person. However, with respect to rune carving he does offer some advice as to the coloring of the runes with pigments. "The vitki [learned one] first carves the runes, signing their names as each is carved, and then reddens them with red dye, paint, or blood" (p. 29). The general trend in this book is to argue that the runes, whether interpreted abstractly or carved physically, represent ancient Germanic insight into reality, which is very reminiscent of List's work. 
All survey respondents described using runes in this most basic fashion of carving. One respondent stated that he uses runes in the fashion which he most considers historically accurate; namely, he marks with runes items that belong to him or were made by him. This particular respondent seems to not utilize runes in any other manner, showing that not all modern Ásatrúers consider runes to be magical. However, one must realize the cultic significance of this respondent's use of the runes as opposed to the Latin-based alphabet for this purpose. Another respondent stated that he carves runes on objects in order to produce the appropriate context for magic and ritual. The fact that he uses runes instead of a more easily accessible Latin-based script demonstrates that he considers runes to inherently lend themselves to magic and ritual. Another respondent stated that he feels it is fitting to carve onto an object either a magical chant in runes or the name of the object's owner in runes. He described his ritual spear: he has carved runes along the shaft and a swastika on the spear itself. Another respondent stated that he carves and colors runes for a variety of purposes. For example, on his drinking horns he carves the sequence alu, which he renders in English as "ale". He also carves the entire fupark on wands. Although some variation exists among respondents, there is a trend to carve runes on items in order to facilitate magical or religious activities.

Divination. Most manifestations of modern runic divination contain some sort of process of randomly selecting certain lots, typically small pebbles from a sack with one rune on each, and interpreting the selection. Another possibility is casting several runic objects onto a particular surface and interpreting how they land. Divination is construed by many Ásatrúers as the runes' most inherent capability. This is perhaps based on the fact that several descriptions of the Germanic peoples from Antiquity make at least some reference to divination, and that many "romantic" scholars today have drawn the link between these references and the fupark. Another 
possibility is that runic divination is relatively accessible and that it would be very beneficial to have the divine insight into life supposedly offered by runes. Regardless of the reasons, vast amounts of published literature on runic divination are accessible, although the survey respondents did not support this use as much as they did the runic carving.

Blum (2008), originally published in 1983, offers the first approach in published literature towards a comprehensive reference for runic divination. Blum considers the runes to be an oracle, and he also seems to consider the divine source of runic insight to be the same source for other cultures' divinatory systems, such as tarot. Blum takes several liberties which, as will be shown, his literary successors did not continue.

Among these liberties exclusively taken by Blum is the addition of a twenty-fifth rune, which he renders as blank and attributes to the unknown mystery of Odin. He also proposes an original sequence for the runes, which begins with the m-rune and ends with the blank rune. One liberty taken by Blum which is continued by his successors is the notion that a backwards or upside-down rune indicates either the opposite of the rune's meaning or the rune's meaning with negative overtones. For example, I summarize Blum's description of the significance of the urune as new beginnings and positive growth. However, the reversed u-rune signifies the failure to take advantage of important opportunities for new beginnings and positive growth. Another of Blum's creative liberties which is continued by other Ásatrú authors is his arrangements for rune spreads. These rune spreads are possible ways of arranging and interpreting runes selected from the fupark during the divination process. One such rune spread requires the rune-user to select three runes. The first rune signifies the overview of the situation; the second rune signifies the challenge; and the third rune represents the action that should be taken. For Blum the runes 
represent a means of communication with the divine, placed alongside other cultural divinations such as tarot and I-ching.

Thorsson (1988) is a comprehensive volume on the act of runic divination itself. The general tendency of this book is to offer the rune caster practical and applicable knowledge of the runes and be a complementary volume to his other publications, which deal mostly with theoretical and abstract notions of runes. Thorsson first explores some of the ideas he considers of utmost importance to rune casting, offers a commentary on the meaning of each rune, and finally describes specifics on the actual act of rune casting.

One such important idea for Thorsson is his concept of ørlög, which is an Old Norse word translated by Thorsson as "primal laws" (p. 15). Contained in this ørlög is the notion that all actions are predetermined. This is crucial for his theory of rune usage. Thorsson takes his ørlög concept a step further and applies a very Listian approach to it. Namely, he links the word with the English word ordeal, which he renders as "primal-deal", 9 and this means that future actions have already been dealt out (p. 15). Thorsson also sees runic significance in the fact that Germanic languages do not possess a grammatical or morphological way to convey futurity; in other words, a verb in any Germanic language can be conjugated in both the present and past tenses, but the verb must be accompanied by a modal verb in order to create the future tense. Thorsson considers this grammatical feature of the Germanic languages to be significant with respect to ørlög; that is, the Germani not only considered the future to be hypothetical compared to the present and past but also considered the future to be predetermined by higher forces. Ultimately, Thorsson considers rune casting as a means of communicating directly with these higher forces in order to gain insight into the future.

\footnotetext{
${ }^{9}$ Thorsson reads the or- of ordeal as a separate morpheme reflecting the Germanic prefix represented in Modern High German Ur-, as in Urzeit "primitive times" or Urmensch "primitive or prehistoric human".
} 
With respect to the commentary on each rune's meaning, Thorsson follows a similar format as Blum (2008), with the exception that Thorsson follows the sequence of the "standard" fubark. Like Blum, Thorsson describes generally what each rune implies and also describes how each rune implies something opposite when it is upside-down or backwards. One significant difference between the two is that Thorsson also provides the relevant stanzas of the various rune poems for each rune. A final difference is that Thorsson does not provide a blank rune.

After a discussion about the theoretical aspects of rune casting, Thorsson moves on to the practical concepts. For example, he comments on the tools necessary for rune casting. Most important here are the physical objects used in divination. Thorsson makes the point that a rune caster does not need delicately made items for casting; one could simply write the runes on twenty-four slips of paper because "the magic is in the self of the runester, not the objects" ( $p$. 67). Thorsson does suggest that the rune caster create one of five types of rune objects: small round pebbles or pieces of wood, rectangular slips of wood, short twigs, long twigs, or cards. With respect to the runic lots themselves, Thorsson makes the final point that they should be colored. Interesting is that Thorsson also describes at length the ritualized processes of not only cutting the twigs off trees for use as lots but also loading magical powers into the runic shapes carved onto the lots. Essentially these are both done by means of focusing on the wights, or innate spirits of the trees, and offering a particular formalized utterance to the wights and to the gods.

Ultimately Thorsson culminates his book with the specifics of the act of rune casting itself. The basic structure for all of Thorsson's lot casting techniques seems to draw from the description provided in Chapter 10 of Tacitus's Germania; all casting of lots are to be done on a white cloth. The obvious difference between Tacitus's description and Thorsson's description is 
that Thorsson explicitly states that objects with the fupark members are to be used in the process. As argued in Chapter 2 above, Tacitus does not make this remark.

Thorsson essentially offers three methods of runic divination. The first is very reminiscent of Blum (2008). Here Thorsson states that the rune user should cast the runes onto a white cloth and randomly select three. The chosen runes are then laid out in a spread in which the first rune symbolizes the past, the second rune symbolizes the present, and the third rune symbolizes the future. Interesting is that Thorsson makes a point to use the Norse terms $U r d h r$, Verdhandi, and Skuld for past, present, and future respectively (p. 94). He calls this method the Nornic Runecast.

Thorsson's second approach to rune casting is referred to as the Casting upon the Airts Method. In this method the rune caster is to cast all the runes onto a white cloth, and each rune is to be interpreted with respect to where it lands on the cloth. The areas of the cloth are to be divided into regions representing the different places in the Norse cosmology, with such places as Niflheimr, Muspellsheimr, and Hel. In the middle of the cloth is significantly Midhgardhr. Thorsson refers to these cosmological regions as "World-Steads" (p. 100).

Thorsson's final significant approach to rune casting is the Laying in the Futhark [sic] Method. In this method the rune caster is to randomly lay the runes in a sequence. Where a given rune is placed in this sequence is then to be compared with what rune occupies that position in the "standard" fupark. In an example reading the z-rune is placed in the position regularly occupied by the n-rune. Individually Thorsson interprets the z-rune as dealing with one's relation to divine forces and the n-rune as need or resistance. Therefore, the occupation by the z-rune of the n-runes position is interpreted as "resistance from archetypal forces within" ( $p$. 107). 
Thorsson's book is both similar to and different from Blum's book. A primary difference is that Thorsson does not branch out into other cultures like Blum does. Instead, he remains within the scope of the Germanic culture. Another difference is that Thorsson does not consider the runes to so much provide insight into the future, but rather to provide insight into the present to allow the rune caster to make better decisions about the future. This is evidenced by his explanation of the Germanic people's hypothetical view of the future. However, like Blum, Thorsson considers the runes as a means of communicating with the divine forces shaping reality.

Plowright (2006) comments about the use of runes for divination. However, Plowright is likely the least "romantic" author examined in this survey of modern Ásatrú literature. When discussing the importance of context with respect to runes, he first acknowledges that there is very little existing information from European history concerning runes, and that many prominent scholars do not believe the runes were ever used for magical purposes. Plowright then explains that some Ásatrúers believe there was a secret and magical cult in Germanic times that dealt exclusively with rune magic. "Somewhere between the extremes is a position where we can find reasonably solid ground on which to build" (p. 6). Plowright devotes much of his books to presenting the runic poems and offering basic interpretations for each rune's meaning. $\mathrm{He}$ does also briefly comment on the techniques of divination and rune magic. Essentially for the act of divination Plowright draws significantly from the description offered by Tacitus, with the obvious exception that Plowright explicitly describes using runes in the act of lot casting, while Tacitus leaves the reader wondering exactly what symbols were used in the act. Plowright's modest description of runic divination portrays runes as a means of communication with the divine. 
Based on the content of survey responses, this divinatory use of runes is secondary, despite the thorough discussion of divination in published literature. One respondent stated that he casts runes when the need arises. He made it clear that he would likely not cast runes for anyone other than himself, a family member, or a member of his kindred. Furthermore, he stated that he uses a method that he has developed himself. This shows that he considers the runes to be something esoteric; not only are his rune readings done privately, but he also uses a private method. Another respondent admitted that there exists absolutely no scientific evidence that runes can perform magic; however, he was certain that the runes work for him and that they have offered him extremely reliable guidance. A synthesis of these two descriptions is that runic divination is something private and esoteric whose effectiveness cannot be scientifically explained.

Meditating and hallowing. Using runes for meditating or hallowing is the most difficult construct of this study to measure because it can have various manifestations. The gamut runs from something as simple as carving runes for the purpose of decoration to consciously contemplating a rune's meaning for the purpose of better understanding and wielding the powers of the cosmos. The simple uses of decoration clearly overlap with the basic notion of carving runes on items described above. However, the cohesion of this section lies in the idea of using runes to focus one's thoughts on the divine. Possibly because of the elusiveness of this aspect of rune usage, Thorsson is the only modern runic author who authoritatively and thoroughly comments on this aspect of rune usage. Nonetheless, survey respondents also commented at length about this use of runes.

Thorsson (1984) is the primary published work dealing with this type of rune usage. Thorsson argues that runes provide the rune user with access to the powerful forces existing in 
the universe. By describing rune magic and explaining how one might be able to wield it, Thorsson is already making the assumption that runes inherently have magical qualities. These magical qualities of runes, however, differ in a significant manner from the magical qualities described by other Ásatrú authors, including other publications by Thorsson. Thorsson (1984) describes the function of runes not as producing magic themselves, but rather as channeling magical powers that exist in the universe independent of the runes. Thorsson's work is essentially a program that the rune user can employ in order to cause the runes to channel these powers.

Thorsson (1984) follows what has become standard practice for published literature on rune lore in that he offers thorough commentary for each rune in the fupark sequence. The peculiarities of this format include the galdr, the stadha, an interpretation of each rune's shape, and the workings each rune can produce. Also included in the format is the traditional meaning of each rune - that is, what ideas are associated with each rune. The galdr is a chant to be recited for the invocation of the rune. This typically includes the rune's name along with sequences of sounds providing alliteration. The stadha is the physical posture one is to assume for the invocation of the rune. This typically uses the person's limbs in order to mimic the runic shape. Also included in the explanation of the stadha are instructions as to which cardinal direction one is to face when assuming the stadha. Thorsson also attempts to show how each rune's shape is related to the rune's meaning. For example, the shape of the f-rune, whose name in Modern English can be translated as either cattle or wealth, is interpreted as "the horns of bovine livestock" (p. 20). Thorsson's inspiration for each rune's magical workings is substantially less transparent. For example, the same f-rune has the magical working of 
"[d]rawing the projected power of the sun, moon, and stars into the personal sphere" among other workings (p. 22).

After a discussion about the properties of the twenty-four runes, Thorsson then attempts to elucidate what exactly this power is which runes can channel. Crucial to his theory of magic are his ideas of the "streams of runic force" (p. 75). According to Thorsson, there are three kinds of such streams: terrestrial, heavenly, and chthonic. The terrestrial streams exist on the surface of the Earth, the heavenly streams exist in the atmosphere, and the chthonic streams exist below the surface of the Earth. Thorsson admits in the course of his explanation that the term 'stream' may be somewhat misleading, refining his description by stating that the runic forces can be felt as sensations within the psyche of the rune user. Furthermore, "[o]nce contact has been made, it will be unmistakable" (p. 76). Contact with these streams or sensations is the fuel of runic magic, and it is this contact which the fupark allows.

Following his clarification of the qualities of rune magic, Thorsson offers the rune user some descriptions of actual runic exercises for either the training or the employment of one's runic abilities. There is substantial overlap in the requirements of the rune user for these various exercises, including the envisioning of the runic shape, the recitation of a chant (galdr), the controlling of one's breathing, and the assuming of particular runic stance (stadha). In the exercise of signing the runes, the rune user moves the hand in the shape of a given rune, helping himself or herself to visualize the rune and also "melding that rune with the symbolic 'target' that has been formulated by the hugr [mind] of the vitki by concentrated visualization, thus bringing about a change in that target" (p. 133). Another exercise is runic meditation. When meditating the rune user is to perform a ritual similar to the signing exercise but with the goal of allowing the rune to speak to him or her. The purpose is ultimately to gain insight into the runic 
mysteries. When commenting on another runic exercise, namely rune yoga, Thorsson stresses the importance of the stadha and makes a statement which well summarizes his arguments in this work: "This can result in the embodiment of the entire runic mystery in the flesh of the vitki, thereby turning the body into an awesome magical tool!” (p. 125).

As stated above, the overall trends in Thorsson (1984) differ somewhat from those of other works mentioned in this chapter. Instead of arguing that runes are a means of communication with the divine, Thorsson argues that runes are a doorway into the mysterious magic of the cosmos. In fact, this doorway is used by the divine and humans alike. In doing so, Thorsson posits that runic magic is in fact independent of the fupark. Although Thorsson is proposing something similar to the "skeptical" view laid out in chapter 2 with respect to the fubark and the Hällristningar, he stresses that this runic magic is primarily accessible through the use of the fupark, thereby positioning himself squarely with other "romantic" Ásatrú authors.

The more abstract notion of runic hallowing and meditation is thoroughly discussed in the surveys. One respondent stated plainly that runes can hallow or make an object or area sacred. Another respondent stated that he has a z-rune as well as an o-rune hanging over his indoor altar. This demonstrates that the orthographic symbols of the fupark are important for Ásatrú rituals. Another respondent placed emphasis not only on runic meditation but also on when he meditates on runes. He stated that certain times of the year, such as Yule, are more appropriate for this kind of meditation. This demonstrates the link existing between the fupark and the religious aspect of Ásatrú. Another respondent described how he uses runes to hallow an area for a Blot ritual, which is a ritual involving a sacrifice. He inscribes the runic shapes in the air. He begins facing north and rotates slightly for each rune, so that he finishes facing north again. This is very reminiscent of Thorsson's (1984) instructions. Another respondent described 
a runic chant he performs for protection. He assumes a posture similar to the z-rune and utters an invocation to the god Thor; again one can easily see similarities between this act and the writings of Thorsson. Collectively these selected survey responses all point to the notion that the runes are useful if not necessary in the creation of the appropriate setting for Ásatrú rituals.

Skepticism. It is interesting that not all survey respondents displayed agreement with respect to the purpose and uses of runes. One respondent explicitly expressed his own skepticism about runes' mystical powers. He believes that runes cannot provide the insight into Ásatrú that rune users are seeking, and he instead places value on religious texts such as the Eddas. This respondent also stated that runes are exclusively alphabetic characters and not magical tools. Another respondent was very skeptical about the divinatory process of lot casting. He stated that this casting of the runes is an almost completely modern notion. This demonstrates that he must not think the fupark was used in the Germanic rituals like the ones described by Tacitus and Caesar discussed in chapter 2 .

\section{Meanings of Individual Runes}

The notion that each rune possesses not only a phonological representation and a name but also a meaning is first attested by the rune poems. This tradition has been strongly continued in the published Ásatrú literature. However, the information conveyed in the rune poems is quite modest compared to the information in modern publications. It is crucial for this study to analyze how modern Ásatrúers consider the runes not only collectively but also individually. Therefore, a synthesis drawing from the consistencies in the publications will be produced for each rune of the elder fupark. This synthesis, however, is not meant to be authoritative; it merely represents the common themes prevailing in the published literature. The published literature compiled here, from most "skeptical" to most "romantic", is Plowright (2006), Fitch (1990), 
Blum (2008), Thorsson (1988) and Thorsson (1984). An interesting characteristic of Thorsson's publications is his frequent assumption of sexual connotations when discussing the runes' meanings.

Fehu. The f-rune is associated with money and mobile property, especially with respect to the accumulation and attainment of wealth. Key here is that the resistance to share one's possession results in destruction and sorrow. Also important is the conservation of wealth that has been attained. This rune has another aspect, namely cattle or livestock. The natural power of these hoofed animals is interpreted as the raw energy of the creation, sustaining, and destruction of the universe.

Uruz. The u-rune is associated with the aurochs, which is an extinct species of ox that inhabited Europe. This animal, like the livestock of the f-rune, is associated with the power of nature. However, modern Ásatrú authors go one step further in their interpretation of this rune and posit that it represents the power within humans to affect change in Midgard. An alternative meaning of this rune thus deals with human beings' ability to courageously defend themselves and to bring about new beginnings in their lives. With these two ideas, namely bovine strength and new beginnings, Thorsson $(1984,1988)$ draws associations between this rune and Audhumla, the cosmic cow that licked icy salt and eventually created the universe.

Purisaz. The p-rune is associated with unsophisticated strength, such as Giants or Thor with his hammer Mjöllnir. The relevance for humans is that this unsophisticated strength may be employed for the removal of obstacles or other unfriendly forces. Plowright (2006) makes the comment that once this force is unleashed, though, it may not be easily controlled. Blum (2008) also discusses non-action when faced with a decision, which he metaphorically describes as a gateway. In other words, Blum argues that when presented with the opportunity to progress or 
pass through a gateway, this rune stresses that one should wait and contemplate the situation thoroughly before making a rash decision. Along quite different lines, Thorsson (1984) emphasizes that this rune carries connotations of love magic and phallic power. Such discord about a rune's meaning is, however, typical when the rune poems differ greatly from each other, as is the case with the p-rune.

Ansuz. The a-rune is associated with the god Odin and divine messages. According to Ásatrú belief, Odin discovered the runes and relayed their wisdom to humans. Humans, in turn, now have the ability to relay sophisticated messages to each other. This can also manifest itself as the ability to influence others through one's speech. Plowright (2006) states that this rune may symbolize the study of the runes themselves. Interesting is that Blum (2008) associates this rune not with Odin, but with Loki, arguing that scoundrels such as Loki can bear wisdom and insight.

Raido. The r-rune is associated with journeys, traveling, or the physical act of riding. This journey may be spiritual and metaphorical, in the sense of a religious journey from reality to the divine, or it may be literal, with emphasis on the physical aspects of journeying such as a horse or an automobile. With respect to spiritual journeys, Thorsson $(1984,1988)$ stresses the importance of correctly ordered ritual. He also argues that this rune can signify the tuning of one's inner rhythms with the rhythms of the universe and thereby aligning one's own self with the divine. This rune, according to Thorsson, could also signify a cosmic journey, such as the sun's daily journey across the sky. A final note on this rune is that it may represent the insight or advice gained during a spiritual quest.

Kenaz. The k-rune is associated with a torch, a controlled fire, or a sore. As with the prune, the surviving rune poems offer substantial discord in their discussions of this rune; 
however, some consensus among modern Ásatrú authors can be discerned. The general theme among these authors is that the $\mathbf{k}$-rune symbolizes the enlightenment or realization gained when a controlled fire illuminates—both literally and metaphorically—a situation. Thorsson (1984, 1988) also stresses the notion that the combination of a divine fire and human control is the source of human creativity.

Gebo. The g-rune is associated with gifts and appreciation of gifts. This rune can represent any of the four primary components of the act of giving: the person giving, the act of giving, the object given, and the recipient. A common theme among the modern Ásatrú authors is that gift giving was always reciprocal in the ancient Germanic culture; that is, when one gave a gift, he expected to receive a gift in return. This reciprocal gift giving resulted in the developments of strong partnerships and loyalty. Thorsson (1984) reads into this the sexual unity that can be created between a man and a woman through the act of giving gifts.

Wunjo. The w-rune has significantly less diverse associations than the aforementioned runes. Essentially, the w-rune is associated with joy and the lack of suffering. This lack of suffering can refer to the cessation of a previously existing suffering or the imminent ceasing of a currently existing suffering. Plowright (2006) considers an important meaning of this rune to be the appreciation of what one has, arguing that the Germanic peoples were often wanting and were very appreciative of the times when they were not wanting. Thorsson $(1984,1988)$ also emphasizes the harmonious fellowship that can exist among relatives or members of a single clan.

Hagalaz. The $\mathbf{h}$-rune is associated with the precipitation hail and its destructive forces. This destruction, however, causes one to grow and become stronger. In this way, modern Ásatrú authors capture a duality that hail is a destructive kind of precipitation but that precipitation 
brings water, which symbolizes new life. Both Plowright (2006) and Thorsson (1984) stress that this rune signifies a balance of opposite powers. Thorsson $(1984,1988)$ interprets this rune as also pointing to a notion of an egg or a seed. Indeed, eggs and seeds bring new life into the world.

Naudiz. The $\mathbf{n}$-rune is associated with need and the necessity of pain in the world. Overcoming this pain and distress can lead to personal growth. Also important is the concept that one should take advantage of delays caused by obstacles to address some other issue. Fitch (1990) not only understands this rune as symbolizing distress but also the lesson one learns from distress. Blum (2008) posits the optimism associated with the $\mathbf{n}$-rune in a somewhat different manner; he stresses that the word "suffering" originally had the meaning of "undergoing". In other words, when one is suffering, one is merely undergoing some phenomenon.

Isa. The $\mathrm{i}$-rune is associated with ice. This rune has many interpretations that are similar to the $\mathbf{h}$-rune and the $\mathbf{n}$-rune. Because ice can be destructive and can impede travels, the $\mathbf{i}$-rune also bears the connotation of obstacles that create delays. However, the modern Ásatrú authors consider the outcome of this rune as different from the previous two. The i-rune points to one's own internal will and power to control malicious outside forces. Thorsson (1984) draws associations between this rune and certain aspects of the Ásatrú creation myth; the i-rune represents the antimatter that emanated from Niflheimr, while the f-rune represents the energy that emanated from Muspellheimr. When these two forces came into contact with each other, the matter of Midgard was created.

Jera. The j-rune is associated with a year or a good harvest. Implied in this rune's meaning is also the idea that a year is cyclical. Thorsson (1984) draws the interesting distinction between this rune, symbolizing the sun's yearly cycle, and the r-rune, symbolizing the sun's 
daily cycle. Significant in this distinction is that the j-rune is associated with long durations of time. The rune's meaning of a good harvest, for example, requires a farmer to work for months before the harvest. This agrarian notion is generalized by the modern Ásatrú authors to apply to any long-term project, and this rune is interpreted to signify that the project will yield great rewards. The authors also stress the importance of patience during the project. Thorsson (1984) argues that the great rewards attained through patience and hard work are merely part of the natural order of the universe as dictated by the Norns, the supernatural beings who weave the destinies of men and gods.

Eihwaz. The æ-rune is associated with the yew species of tree. The modern Ásatrú authors stress that the yew tree produces wood that is very strong and stable yet resistant to fire. Therefore, this rune is interpreted to also mean protection and defense. An important additional step in interpreting this rune is that one grows and gains strength when defending herself or himself. Thorsson $(1984,1988)$ also sees Yggdrasil, the World Tree of Norse mythology, as associated with the æ-rune. According to Thorsson, because the god Odin was hanged from Yggdrasil to gain divine knowledge, this rune symbolizes the rituals one must undergo in order to become initiated as a shaman.

Perthro. The p-rune is associated with games of luck and chance. Because this rune did not exist in the younger row, only one stanza from the Old English rune poem exists as an explanation for this rune. Therefore, the authors' individual interpretations of this rune differ greatly. Thorsson $(1984,1988)$ sees this rune as symbolizing the act of lot casting itself. For Thorsson, then, this rune points to his idea of ørlög, which he likens to the Hindu concept of karma and contrasts to the Christian notions of fate and predestination. Blum (2008) sees this rune as a phoenix, a mythical bird which consumes itself in fire and rises from its own ashes; 
significant is that the phoenix is historically not a part of Germanic mythology. This demonstrates not only Blum's readiness to incorporate other cultures into his runic program but also the fact that modern Ásatrú authors create various interpretations that differ significantly than the runes' meanings in the Scandinavian and English rune poems.

Elhaz/Algiz. The z-rune is associated with either elks or with protection. This confusion is due to the absence of this rune in the Norse and Icelandic rune poems. As with the p-rune, the z-rune only has a stanza in the Old English rune poem. The notion of protection, however, is the most prevalent meaning among the modern Ásatrú authors. The authors all argue that this rune entails the necessity of controlling one's own emotions during times of distress that call for defensive action. Thorsson (1984) also considers this rune to signify the rainbow bridge Bifröst, which connects the realm of humans with the realm of the gods. The z-rune can, according to Thorsson, also assist in bringing human consciousness closer to the gods.

Sowilo. The s-rune is associated with the sun. The modern Ásatrú authors stress the fact that in the ancient Germanic languages, as is still often the case today, the noun for "sun" was grammatically feminine. The s-rune is also considered to represent victory. Thorsson (1984) therefore collapses femininity and victory into the concept of the Valkyries. Thorsson also draws the distinction between sól, which is indicative of the physical sun, and sunna, which is indicative of the spiritual power residing in the sun. Thorsson (1988) furthermore explains how the s-rune is the benevolent counterpart to the malicious i-rune.

Tiwaz. The t-rune is associated with the Norse god Tyr. According to Norse mythology, the gods wanted to bind and fetter the ferocious wolf Fenrir. Fenrir agreed on the condition that he could hold in his mouth on of the gods' hands. Tyr was the only god brave enough to meet this challenge, and Fenrir subsequently bit off Tyr's right hand. Therefore, this rune is also 
associated with self-sacrifice, self-discipline, and self-control. Modern Ásatrú authors also link this rune to justice, as Tyr was the god who presided over the Thing, the Icelandic legal assembly. Tyr was also the god of war, and the authors acknowledge this as an additional facet of the t-rune. Thorsson $(1984,1988)$ also associates this rune with the world-column, which separates heaven from earth. According to Thorsson, destruction would follow should heaven (Asgard) come into contact with earth (Midgard).

Berkana. The b-rune is associated with the birch tree, as well as the Earth Goddess, whom Tacitus calls Nerthus. Because Nerthus is the goddess of fertility, this rune is furthermore associated with birth, rebirth, and growth. Fitch (1990) also associates this rune with the sun, animals, birds, and fish. Thorsson (1984) considers this rune to preside over what he calls the four rites of passage: birth, adolescence, marriage, and death.

Ehwaz. The e-rune is associated with horses. This association can manifest itself in different ways. For example, the modern Ásatrú authors draw attention to the bond of friendship existing between a horse and a rider. This bond can be indicative of a friendship or a romantic relationship. The rune can also symbolize the more abstract concepts associated with these relationships such as teamwork, trust, cooperation, and loyalty. Another manifestation of the notion of horses is that of movement and transportation. Blum (2008) argues that this movement can be physical, as in travel to a new dwelling place, or metaphorical, as in movement towards new attitudes or a better situation. Thorsson (1984) emphasizes the Germanic notion of dual leaders being represented by two horses. He also mentions Sleipnir, Odin's eight-legged horse who can travel among the worlds of Yggdrasil.

Mannaz. The m-rune is associated with mankind and humanity. Essential to the modern Ásatrú writers, this rune expresses the notion that humans are divinely endowed with certain 
traits distinguishing them from other animals. These traits include intelligence, culture, and tradition. A recurring idea for this rune is the advice that a person should be aware of these traits within herself or himself. Thorsson (1984) argues that this rune symbolizes Heimdallr, a Norse god who, according to Thorsson, is the progenitor of mankind. Therefore, this rune signifies for Thorsson the notion that humans are genetically descended from the gods.

Laguz. The I-rune is associated with water, a lake, or a sea. This is seen by the modern Ásatrú authors as the source of fertility, growth, and life. Also stressed by these authors is the fluidity and flowing nature of water. Plowright (2006) states that this water can be likened to the subconscious human mind; both are imperceptible and opaque. Blum (2008) argues that this rune represents a sacred and euphoric marriage, and he compares this with fairy tales that end in blissful marriage. Both Fitch (1990) and Thorsson (1984) maintain that the tradition of sprinkling water on newborn babies is a Germanic tradition predating the Christian tradition and that this tradition is also included in the meaning of the I-rune.

Ingwaz. The $\mathbf{n}$-rune is associated with either the legendary Germanic hero Ing or the Norse god Freyr. In fact, most modern Ásatrú authors argue that Ing and Freyr are one in the same. This rune has connotations of fertility and is the counterpart to the b-rune; however, unlike the b-rune, the $\mathbf{n}$-rune is associated with male fertility. Frequently the $\mathbf{n}$-rune is compared to the notions of nature, peace, and resting. Blum (2008) considers this rune to symbolize the completion of a project. Thorsson $(1984,1988)$, on the other hand, considers this rune to symbolize the gestation of a project. He also argues that this rune signifies eastward movement, and that the East is where giants live.

Dagaz. The d-rune is associated with day and daylight. This daylight is subsequently associated with revelations, awareness, and clarity. Here daylight is interpreted metaphorically 
with the connotation of dispelling the ignorance that exists during the reduced visibility of night. Fitch (1990) likens this rune to royalty and nobility. Thorsson $(1984,1988)$ considers this rune to represent both day and night; the d-rune signifies not only the notion of polarity, but also how polar opposites may be viewed and furthermore understood in metaphorical daylight.

Othala. The o-rune is associated with inheritance or immobile property, which can be something tangible such as an estate or something abstract such as genetics and tradition.

Modern Ásatrú authors see significance in the fact that the o-rune is the final rune of the fupark, while the f-rune, representing mobile property, is the initial rune of the fupark. Blum (2008) interprets this rune to symbolize separation and the necessity to discard outmoded relationships. Thorsson (1988) states that this rune, with its connotations of the social act of inheriting, is associated with social order and furthermore with freedom. Thorsson (1984) argues that the orune can serve as a monogram for the god Odin.

\section{Discussion}

Although noteworthy variation and even skepticism exists within the modern Ásatrú society with respect to runes and their abilities, certain significant trends can be described. Collectively the runes have gained a myriad of religious and magical functions, which I have categorized as being carved, divination, and hallowing; the runes are collectively viewed as a means of communication with the other-worldly or divine. The individual runes gained multifaceted meanings with strong religious, psychological, and social overtones. This conception of runes held by modern Ásatrúers stands in stark contrast to the conception of runes held by the Germani, who viewed them as a utilitarian writing system. 


\section{Chapter 5: What You Actually Do with Runes}

In the previous chapters I established the sharp difference between historical and modern rune usage. Historical rune usage was primarily utilitarian and devoid of magical qualities, whereas modern rune usage is based on a magical and religious understanding of the characters. Because this difference is based on specifically how runes were used and to what purpose, one can better understand both historical and modern rune usage by applying what Austin (1962) refers to as speech act theory. The purpose of this chapter is to substantiate by means of Austin's theory that runes historically had non-magical functions, while present-day Ásatrúers utilize runs for magical purposes. This difference regarding what runes accomplish runs counter to the claim of influential Ásatrú writers, discussed in the previous chapter, that modern Ásatrú rune usage is a faithful recreation of historical rune usage.

The method I use in this chapter, although not the conclusion I reach, greatly resembles work such as Flowers (1986) and especially Flowers (2006). In these works Flowers propagates the notion that significant evidence exists in the older runic corpora to posit magical intentions behind at least some of the surviving runic texts. However, I will support the "skeptical" viewpoint by uncovering a considerable fallacy in the "romantic" argument, namely that the historical purpose of runes is to alter reality by means of rune usage. An additional purpose of this chapter is to give a linguistic account of the notion of magic itself. Speech Acts

As laid out in Austin (1962), speech almost always carries an additional purpose other than simply informing the audience. According to his speech act theory, any given verbal utterance has three forces: locutionary, illocutionary, and perlocutionary. For the purposes of this chapter, Austin's theory will be expanded to include also written language so as to 
accommodate surviving runic texts, as was done in other publications that applied Austin's theory to runes, such as Flowers (2006) and Zimmerman (2010). Modern runology is at a loss because a rune carver who lived over one thousand years ago cannot be questioned regarding his intent when carving. However, certain trends emerge if one makes pays attention to significant contextual information concerning the creation of the text without positing any ungrounded assumptions for the sole purpose of defending what one believes before doing any research. Another significant adjustment to Austin's theory pertains to the fact that rune usage is rarely if ever verbal speech. Attested historical rune usage exists exclusively as written texts, while modern rune usage ranges from written texts to runic divination and meditation. Nonetheless, for both historical and modern rune uses, locutionary, illocutionary, and perlocutionary forces can be determined to a degree of certainty, as will be shown below.

The three forces can be best explained through the modern-day example of a no-parking sign containing the text "Violators Will Be Towed". Such a sign also bears relevant similarities to particular sections of the Björketorp and Stentoften inscriptions (see Figures 18 \& 19) to be discussed below. The locutionary force of speech is the traditionally grammatical description and explanation. Austin writes that the locutionary force "includes the utterance of certain noises, the utterance of certain words in a certain construction, and the utterance of them...with a certain sense and with a certain reference" (p. 94). In the example of the parking sign, the locutionary force would include such information as the plural subject, the future tense, the passive voice, the spelling of the words, etc. The illocutionary force is the intent of the speaker in when making the utterance. Austin explains that the illocutionary force entails "performance of an act in saying something as opposed to performance of an act of saying something" (p. 99). The illocutionary force of the parking sign is to permit the towing of improperly parked cars. 
The perlocutionary force is what effect the utterance is meant to have. Austin states that the perlocutionary force produces "effects upon the feelings, thoughts, or actions of the audience, or of the speaker, or of other persons" (p. 101). The perlocutionary force of the parking sign example is to persuade drivers to not park in the area designated by the sign.

Because neither historical nor modern rune usage is necessarily oral, how these forces relate to rune usage must be made explicit. The locutionary force is the grammatical structure of the runic text, including the orthographic shapes of the signs, and the physical details of modern runic rituals. The illocutionary force is the intent of the rune user. The perlocutionary force is the way in which reality, including both the audience's thoughts as well as circumstances of the physical world, is altered by the runic text.

\section{Application of Speech Act Theory}

For this study the speech act theory will be applied to three kinds of rune usages: historical utilitarian, historical ephesia grammata, ${ }^{10}$ and modern. The Lindholm amulet (see Figure 11) and the Gallehus horn (see Figure 20) will be examined as historical utilitarian examples. The Lindholm amulet also contains an example of ephesia grammata. This particular text was selected because it was also used by Flowers (2006). In this way, particular fallacies in Flowers's work can be illuminated. The Gallehus horn was selected because, although the language of the runic text bears little difficulty in translating, the features of the horn itself provide interesting insight into the purpose of the text.

The inscription on the Lindholm amulet is translated as "I, the erilaz, am called Sawilagaz [i.e. the sunny, bright one]....Magic" (Antonsen 1975, p. 37) or as "I, the eril (= runemaster) am called the crafty one" (Flowers 1986, p. 206). The inscription on the Gallehus horn

\footnotetext{
${ }^{10}$ The ephesia grammata are the pieces of runic text which do not spell any known word and are discussed in the third chapter.
} 
is translated as "I, Hlewagastiz [i.e. protected or famous guest], son of Holtagastiz, made the horn" (Antonsen, p. 41) or as "I, Hlewagast Holt (i.e. man of the grove), (or, descendant of Holt), made the horn" (Flowers, p. 195). The remaining locutionary forces, which pertain to the grammar, of the Lindholm amulet and the Gallehus horn have been exhaustively discussed by both Antonsen and Flowers and only relevant aspects will be reproduced here.

Before discussing the forces of these two runic texts, some speculation regarding their contexts is necessary. Because the Lindholm amulet was discovered in a bog, Flowers (2006) argues that the Germani intended the text on the amulet to '[be] 'sent' to a place where the formula could best be 'read' - and thus have its operative effect" (p. 79). However, given the collection of very mundane and non-religious runic texts carved on objects found in other bogs, it does not seem likely that the Germani typically assumed that objects placed in bogs would be read by bog-dwelling beings (Page 1987). Why and how exactly these objects ended up in a bog is unknown. Page suggests that the Germani may have sacrificed these objects as a part of a religious ritual. However, the assumption that the texts were carved onto the objects with the sole purpose of placing these objects into a bog is too weak. Many of the runic texts mentioned by Page that were found in bogs are utilitarian. For example, many of the earliest of these texts contain a personal name and are interpreted as the name of the object's creator. These texts can more accurately be described as the craftsmen's trade names or trademarks. Flowers's assumption that any runic text found in a bog should be considered magical does not stand up to the trends of texts actually found in bogs.

The Gallehus horn is a large drinking horn made of gold. Although Tacitus was writing approximately 300 years before the horn was made, he makes the point that the Germani preferred silver coins over gold ones because their typical commercial transactions were more 
easily measured in silver than in gold (Winterbottom \& Ogilvie 1975). By recording this,

Tacitus documents that gold was considered extremely valuable by the early Germani. Because of the golden horn's high monetary value and the fact that the use of a drinking horn is something social, the runic text on the horn must be viewed in the context of significant social prestige. In other words, the author of the text must have known that the horn's owner would have wanted prominent members of society to see the horn, and these prominent members of society would certainly have noticed the runic text.

With respect to the locutionary force of the Lindholm amulet, it is pertinent to examine what is actually in the text. The interpretable section contains some man named Sawilagaz ${ }^{11}$ referring to himself in the first person and giving himself the title of erilaz. Antonsen (2002, pp. 185-191) provides a thorough discussion of the title erilaz, critiquing the "romantic" view that an erilaz was a religious or magical official. Elsewhere in this work, Antonsen comments that "it is not at all certain that the erilaz was an official on the sacral plane, but there is no doubt that he occupied a high position... in the society" and, citing three specific inscriptions, that "the erilaz is identified as a servant or follower of some petty king, or chieftain" (p. 262). The final word, alu, has received various explanations. Because of the fact that it almost always occurs textfinally, I propose that this word serves the function of concluding a linguistic ritual. In this respect it mirrors the modern English word "amen".

Because of the content of the Lindholm amulet, the illocutionary force must have been to establish the authority of the object's bearer. Some man named Sawilagaz can establish that he is indeed an erilaz because he bears this object. In this respect, the amulet resembles the modern police badge, which states the police officer's name — or at least an identification number — and

\footnotetext{
${ }^{11}$ I agree with Antonsen's interpretation that sawilagaz is a single personal name, "Sawilagaz (Sunny)", and not with Flowers's interpretation that this is a definite article followed by a substantivized adjective, "sa wilagaz (the crafty [one])", on the basis that there is no other instance of an article in the elder fupark.
} 
establishes his or her authoritative position. The perlocutionary force, or the social effect of the text on the Lindholm amulet, must have been to convince people that the bearer had some authority. Exactly what this authority was is unknown; however, it is certain that Sawilagaz held the position of erilaz, the local official with the ability to carve runes. The view taken by Flowers (2006) that the author's intent was to channel his authority and craftiness to perform some rune magic is founded on too many assumptions to have true merit. The view presented here that the Lindholm amulet was actually a symbol of the office of erilaz is pragmatically much more tenable.

The locutionary force of the Gallehus horn is more straightforward than the Lindholm amulet. According to the text on the horn, a man named Hlewagast Holtsson made the horn. What Hlewagast's intent was — the illocutionary force of the text — is somewhat more elusive; however, it seems that Hlewagast wanted either to declare that he was the horn's maker or to commemorate when he presented of the gift of the horn itself. The perlocutionary force of the Gallehus horn text is to cause people to remember that Hlewagast made the horn. Because the golden horn was probably seen as a prestige symbol, Hlewagast is able to create a place for himself in high society by including his name on the horn itself.

In his program of establishing runes as having some function other than a purely utilitarian one, Flowers (1986, p. 195) points to four characteristics of the Gallehus horn text, three of which I find supporting an argument more grounded in fantasy than in reality. First, this text contains what Flowers called "the ek-formula", meaning that the text begins with the first person singular nominative pronoun $e k$. Flowers argues that in this manner the rune carver can channel his own magical energy into the inscription; I argue that in this manner the rune carver can establish himself as the creator of the horn. Second, Flowers mentions the alliteration of this 
text. Although three of the four content words begin with $\mathbf{h}$, this trend of early Germanic verse may purely have been stylistic and nothing magical. Third, Flowers points to the probable etymology of name holtijaz, related to Modern High German Holz, and references "the possible sacral significance of the grove in Germanic religion" (p. 195). There is no evidence that the Germani placed any more weight on the etymology of surnames than is done today. Flowers's fourth point, while likely true, bears little significance on this discussion; he mentions the horn's cultic function. Although horns like this one were used in social and possibly cultic situations, this use of the horn does not change how one should interpret Hlewagast's purpose in writing the runic text.

The locutionary forces of ephesia grammata are more difficult to ascertain due to the fact that these texts are seemingly uninterpretable and their references are therefore unclear. However, many ephesia grammata such as that of the Lindholm amulet do display some discernable patterns. These ephesia grammata contain eight a-runes, three z-runes, three n-runes, and three t-runes. The cultic significance of the number three is pan-cultural, while the number eight may have a connection with one-third of the fupark row. Clearly these ephesia grammata are not simply random sequences. The illocutionary force of the Lindholm amulet is subsequently also difficult to determine; however, I posit that socially these ephesia grammata served to establish that the writer or bearer of the text was knowledgeable of some esoteric discourse. Flowers (2006) argues that this esoteric discourse is indeed the discourse of the gods. Given that no other aspect of the Lindholm amulet text points to anything magical or sacred, positing such a divine discourse as an explanation of these ephesia grammata seems out of place. The perlocutionary force would then be to convince people that the bearer of the text understands something more sophisticated than ordinary discourse. 
As stated above, the speech act theory must be altered to a greater degree in order to accommodate modern rune usage. However, as was established in the previous chapter, the runic shapes themselves do refer to particular ideas and there is a sort of "grammar" in the particular procedures of lot casting. If the features of modern rune usage described in the previous chapter are taken as a grammar, then locutionary forces can be defined as those features themselves. Because the "speakers" of modern rune usage - that is, the people who use the runes today - have provided not only their intentions of rune usage but also the results, the illocutionary and perlocutionary forces of modern rune usage can be established with great certainty.

Taken as a whole, modern rune usage has various locutionary forces (cf. the previous chapter). These locutionary forces can range from the carving of the runes to the rune yoga described in Thorsson (1984). However, the two remaining forces do not vary to such a degree when all modern rune usage is examined. The illocutionary force of this usage is to request assistance or hidden knowledge from the divine. The perlocutionary force is to predict the future or to gain otherwise unattainable insight into the present. This speech act analysis of modern rune usage supports the notion established in the previous chapter, namely that modern rune usage relies heavily on the notion of magic.

\section{Discussion}

I have defined magic as the ability to alter reality through otherwise unexplainable means. Based on the speech act analysis of rune usage, this definition can be better operationalized. When the locutionary force of an utterance cannot logically create the perlocutionary force and the perlocutionary force is to alter reality, then the utterance may be said to be magical. A simple example can illuminate this point. When a magician utters 
"abracadabra" and pulls a rabbit out of a seemingly empty hat, the audience is made to believe that the utterance is essential to the magician's apparent creation of a rabbit. Crucial to the discussion at hand is that the locutionary force of uttering "abracadabra" cannot scientifically account for the sudden appearance of the rabbit — the perlocutionary force. Therefore, this is an example of magic.

A crippling fallacy of the "romantic" argument can now be exposed. When dealing with texts such as those containing ephesia grammata, the fallacy is not that the "romantics" assume that the locutionary force cannot account for the perlocutionary force. If this assumption were correct, then the texts fulfill the first criterion necessary for being considered magical. Rather, the "romantics" make the assumption that the perlocutionary force is to alter reality, which is the second criterion. However, the perlocutionary force of historical runic texts was not to alter reality, unlike the perlocutionary force in the example above of the rabbit in the magician's hat.

A similar case can be made for the Stentoften and Björketorp stones of the seventh century, both of which seem to condemn to death the potential destroyer of the stones. The relevant portion of the Stentoften inscription is translated as follows: "Protectionless through [because of] baseness, (in possession) of an insidious death is he (who) breaks this" (Antonsen 1975, p. 87). The relevant portion of the Björketorp stone is likewise translated as follows: "Because of baseness, protectionless abroad is, (condemned) to an insidious death, he who breaks this. Harmful prophecy" (Antonsen, p. 88). If it were the case that the Germani believed the runic characters themselves to cause the insidious death, then these inscriptions should be considered magical. However, when considered like the example above of a parking sign, these inscriptions lose all their magical qualities. No motorist believes that the letters on the parking sign are what cause an illegally parked car to be towed away. Similar to the parking sign, it is 
much more likely that the illocutionary force of these stones was to permit authorities to prosecute a vandal who had damaged these stones. The perlocutionary force, moreover, must have been to compel potential vandals to not damage these stones. Assuming a more fantastic perlocutionary force behind these two texts, as well as any other runic text, is the fundamental fallacy of the "romantic" program. 


\section{Chapter 6: Conclusion}

\section{General Conclusions}

In the previous chapters I have demonstrated two key points. First, the texts written in the elder fupark were not intended by the Germani of Antiquity to be magical. These texts convey mostly mundane information and show no strong connection to the act of Germanic divination or to any other aspect of Germanic magic. The "romantic" view lacks validity when one examines the existing evidence with scrutiny and without preconceived notions about the purpose of the runes. Second, modern Ásatrúers employ runes in very religious contexts and consider runes to have magical functions. Modern rune usage exemplifies my operationalized definition of magical utterances because the locutionary forces, which pertains to the shapes of the runes and the procedures of rune rituals, can in no way create the perlocutionary forces, which can be described as assistance from divine powers for altering reality.

\section{Recommendations for Further Research}

Although this thesis has demonstrated with great certainty that a discrepancy exists between historical and modern rune usage with respect to the magical qualities of runes, this study also has shortcomings. A much stronger and more thorough corpus of modern rune usage is required for further research in this field. The corpus compiled here is admittedly modest, and a larger corpus with input from a larger number of practicing Ásatrúers would ensure that the

trends explicated here are generalizable to the whole Ásatrú community. Furthermore, applying a contextualized speech act analysis like the one employed in the fifth chapter to this larger corpus would shed important light on the intentions of the rune users of history. Lastly, to better understand when and how runes were imbued with magic, a deeper literary analysis of medieval 
texts referencing runes is necessary. The purpose of this study is linguistic and not literary; only where those two fields overlap does this study have any literary authority.

\section{Ramifications}

Because the goal of modern Ásatrúers is to faithfully recreate the religion of the pagan Germani, a particular conclusion can be drawn. There must be some reason why certain aspects of early Germanic paganism, especially rune usage, are misunderstood in modern society. I offer a simple explanation: lack of objective research in Germanic studies. Modern Ásatrúers are aware that the Germani used the fupark, and several references from Antiquity illustrate that the Germani also believed in the magical powers of divination. In searching for a tangible anchor on which to attach the abstract notion of Germanic magic, Ásatrúers turn to the fupark. In this thesis I have clarified that this overlap between the fupark and Germanic magic is not historically

accurate, yet it exists among Ásatrúers whose goal it is to practice a faithful reconstruction of historical Germanic paganism. Because the published Ásatrú literature often cites historical works such as the rune poems and Tacitus's Germania, it is clear that Ásatrúers desire to base their religion on authentic historical ideas and not solely on personal spiritual beliefs. Nonetheless, ahistorical rune usage persists. It is my hope that this study will begin to offer runological circles and modern Ásatrúers alike an unbiased and objective account of the runes. 


\section{References}

Antonsen, E. H. (1975). A concise grammar of the older runic inscriptions. Tübingen, Germany: Max Niemeyer Verlag.

Antonsen, E. H. (2002). Runes and Germanic linguistics. New York: Mouton de Gruyter.

Arntz, H. (1944). Handbuch der Runenkunde [Handbook of rune lore]. Halle, Germany: A. Heine Gmbh.

Asatru Folk Assembly (2007). Kindreds page. Retrieved January 13, 2010, from http://www.runestone.org/communication/grove/kindred1.htm

Austin, J. (1962). How to do things with words. Cambridge, MA: Harvard University Press.

Bartlett, R. (2008). The natural and the supernatural in the Middle Ages. Cambridge, England: Cambridge University Press.

Bellows, H. A. (2007). The Poetic Edda: The heroic poems (Trans.). Mineola, NY: Dover Publications.

Blum, R. H. (2008). The book of runes. New York: St. Martin's Press.

Byock, J. L. (1990). The saga of the Volsungs (Trans.). London: Penguin Books, Ltd.

Conner, P. W. (2008). The Ruthwell monument runic poem in a tenth-century context. The review of English studies, 59(238), 25-51.

Davidson, H. R. E. (1988). Myths and symbols in pagan Europe: Early Scandinavian and Celtic religions. Syracuse, NY: Syracuse University Press

De Vries, J. (1960). Kelten und Germanen [Celts and Germanic peoples]. Bern: Francke Verlag.

Düwel, K. (1968). Runenkunde [Rune lore]. Stuttgart, Germany: J. B. Metzlersche Verlagsbuchhandlung. 
Edwards, H. J. (1939). The Gallic War (J. Caesar, Trans.). Cambridge, MA: Harvard University Press.

Elliott, R. W. V. (1959). Runes: An introduction. Manchester, England: Manchester University Press.

Fitch, E. (1990). The rites of Odin. Woodbury, MN: Llewellyn Publications.

Flowers, S. E. (1981). Revival of Germanic religion in contemporary Anglo-American culture. The Mankind Quarterly, 21(3), 279-294.

Flowers, S. E. (1986). Runes and magic: Magical formulaic elements in the older runic tradition. New York: Peter Lang Publishing, Inc.

Flowers, S. E. (1988). The secret of the runes (G. von List, Trans.). Rochester, VT: Destiny Books.

Flowers, S. E. (2006). How to do things with runes: A semiotic approach to operative communication. In Marie Stoklund et al (Eds.), Runes and their secrets: Studies in runology (pp. 65-82). Copenhagen: Museum Tusculanum Press.

Grimm, W. C. (1821). Ueber deutsche Runen [About German(ic) runes]. Göttingen, Germany: Dieterichsche Buchhandlung.

Halsall, M. (1981). The Old English rune poem: A critical edition. Toronto, Canada: University of Toronto Press.

Handford, S. A. (1970). The Germania (C. Tacitus, Trans.). London: Penguin Books, Ltd.

Haugen, E. (1976). The Scandinavian languages: An introduction to their history. Cambridge, MA: Harvard University Press.

Hayes, H. R. (1963). In the beginnings: Early man and his gods. New York: G. P. Putnam's Sons. 
Hopkins, T. J. (1971). The Hindu religious tradition. Belmont, CA: Wadsworth Publishing Company.

Hreinsson, V. (1997). The complete sagas of Icelanders. Reykjavík, Iceland: Bókaútgáfan Leifur Eiríksson.

Kaplan, J. (1996). The reconstruction of the Ásatrú and Odinist traditions. In J. R. Lewis (Ed.), Magical religion and modern witchcraft (pp. 193-236).

Kieckhefer, R. (1989). Magic in the Middle Ages. Cambridge, England: Cambridge University Press.

Klostermaier, K. K. (2007). A survey of Hinduism. Albany, NY: State University of New York Press.

Knirk, J. E. (2009, October 27). Revised preliminary report. Retrieved November 20, 2009, from http://www.khm.uio.no/forskning/publikasjoner/runenews/hogganvik/report-2.pdf

Marsden, R. (2004). The Cambridge Old English reader. Cambridge, UK: Cambridge University Press.

Moltke, E. (1985). Runes and their origin: Denmark and elsewhere. Copenhagen: Nationalmuseets Forlag.

Monaghan, P. (2004). The encyclopedia of Celtic mythology and folklore. New York: Facts On File, Inc.

Page, R. I. (1987). Runes: Reading the past. Berkeley, CA: University of California Press.

Page, R. I. (2006). Anglo-Saxon runes: Some statistical problems. In Marie Stoklund et al (Eds.), Runes and their secrets: Studies in runology (pp. 271-282). Copenhagen: Museum Tusculanum Press.

Plowright, S. (2006). The rune primer. Raleigh, NC: Lulu Press, Inc. 
Reichardt, K. (1953). The inscription on Helmet B of Negau. Language, 29(3), 306-316.

Stallybrass, J. S. (1966). Teutonic mythology. (J. Grimm, Trans.). New York: Dover Publications, Inc.

Terry, P. (1990). Poems of the Elder Edda (Trans.). Philadelphia, PA: University of Pennsylvania Press.

Thompson, E. A. (1965). The early Germans. Oxford: Clarendon Press.

Thorsson, E. (1984). A handbook of rune magic. York Beach, ME: Samuel Weiser, Inc.

Thorsson, E. (1988). Runecaster's handbook. York Beach, ME: Samuel Weiser, Inc.

Thorsson, E. (1994). The truth about Teutonic magic. St. Paul, MN: Llewellyn Publications.

Traupman, J. C. (1966). The new college Latin \& English dictionary. New York: Bantam Books.

Winterbottom, M. \& Ogilvie, R. M. (1975). Cornelii Taciti Opera minora [Minor works of Cornelius Tacitus]. Oxford: Clarendon Press.

Zimmermann, C. (2010). "How to do things with runes": Illocutionary forces and communicative purposes behind the runic inscriptions in the older fupark. Futhark: International Journal of Runic Studies, 1, 85-108. 


\section{Appendix A}

\section{Survey about Modern Rune Usage}

1. In your opinion, what is a rune? How would you define the word "rune"?

2. How often do you use runes?

3. In what contexts do you use runes?

4. How do you use runes? (Do you read them? Do you carve them? etc.)

5. When you use runes, what effect do they have? 


\section{Appendix B}

\section{Figures $^{12}$}

Figure 1. The elder fupark in the standard order. The text reads fuparkgw/hnijæpzs/tbemlndo.

Figure 2. The Einang stone. The text reads:

...dagastiz runo faihido

“(I),...dagastiz, painted the rune"

Figure 3. The Järsberg stone. The text reads:

ek erilaz ... ubaz hite harabanaz hait ... runoz waritu

"I, the erilaz, am called [Le]ubaz, write the runes. $\mathrm{H}^{\mathrm{a}} \mathrm{rab}$ anaz (is buried here)."

Figure 4. The Rö stone. The text reads:

swabaharjaz sairawidaz [ek] stainawarijaz fahido ek hrazaz satido [s]tain[a] ana ... $r$...

"Swābaharjaz with gaping wound. (I), Stainawarijaz, painted (it). I, Hrazaz, set the stone on ..."

Figure 5. An example of the Hällristningar.

Figure 6. The Negau B Helmet. (Reichardt 1953) The text reads:

HARIXASTITEIVA///IP

"Harigasti [personal name] Teiwa [The god Tyr]..."

${ }^{12}$ All transliterations and translations, unless otherwise cited, are taken from Antonsen (1975). 
Figure 7. The Øvre Stabu spearhead. The text reads:

raunijaz

"Tester"

Figure 8. The Kårstad stone. The text reads:

ek aljamarkiz baijaz

"I, Aljamarkiz, (am) a warrior"

Figure 9. The Thorsberg Scabbard. The text reads:

owlpupewaz ni waje mariz

"Wolpupewaz of immaculate repute"

Figure 10. The Møjebro stone. The text reads:

ana hahai slaginaz frawaradaz

"Slain on (his) steed, Frawarādaz"

Figure 11. The Lindholm amulet. The text reads:

ek erilaz sawilagaz hateka : aaaaaaaazzznnn*bmuttt : alu :

"I, the erilaz, am called Sawīlagaz ... Magic"

Figure 12. The Fyn 1 bracteate. The text reads:

horaz lapu aa[d/p]raaaliiu alu

"Hōraz. Summons ... Magic" 
Figure 13. The Hogganvik stone. (Knirk 2009) The text reads:

[s]kelbapewas stainaz aasrpkf / aarpaa inana naloz / ek naudigastiz / ek erafaz

“Skelba-pewaz's stone ... / ... from within the wheel-nave / I, need guest / I, Wolverine"

Figure 14. The Charnay fibula. The text reads:

fuparkgwhnijæpzstbem up fapai iddan liano

"(fupark) To [my] husband, Iddo. Lianō"

Figure 15. The Kowel spearhead. The text reads:

tilarids

“Goal-pursuer"

Figure 16. The Yarmouth stone. The text is not decipherable.

Figure 17. The Krogsta stone. The text reads:

mwsæeij* / sæainaz

“... stone"

Figure 18. The Björketorp stone. The text reads:

hAidzruno ronu fAlAhAk hAiderA ginArunAz ArAgeu hAerAmAlAusz uti Az welAdAude sAz pAt bAruty upArAbA sbA

"The sequence of bright runes I commit here, mighty runes. Because of baseness, protectionless abroad is, (condemned) to an insidious death, he who breaks this. Harmful prophecy." 
Figure 19. The Stentoften stone. The text reads:

ni uhA borumz ni uha gestumz hApuwolAfz gAf $\mathrm{j}$ hAriwolAfz mag[i]u snuh*e hidezruno no felAhekA hederA ginoronoz herAmAlAs Az ArAgeu welAduds sA pAt bAriutip

"Not Ūha to the sons, not Ūha to the guests, [but] H pwul'fz gave good-harvest. Hæriwul'fz

[to] his son ... The sequence of bright runes I commit here, mighty runes. Protectionless through

baseness, [in possession] of an insidious death is he [who] breaks this.

Figure 20. The Gallehus horn. The text reads:

ek hlewagastiz holtijaz horna tawido

"I, Hlewagastiz, son of Holtagastiz, made the horn." 


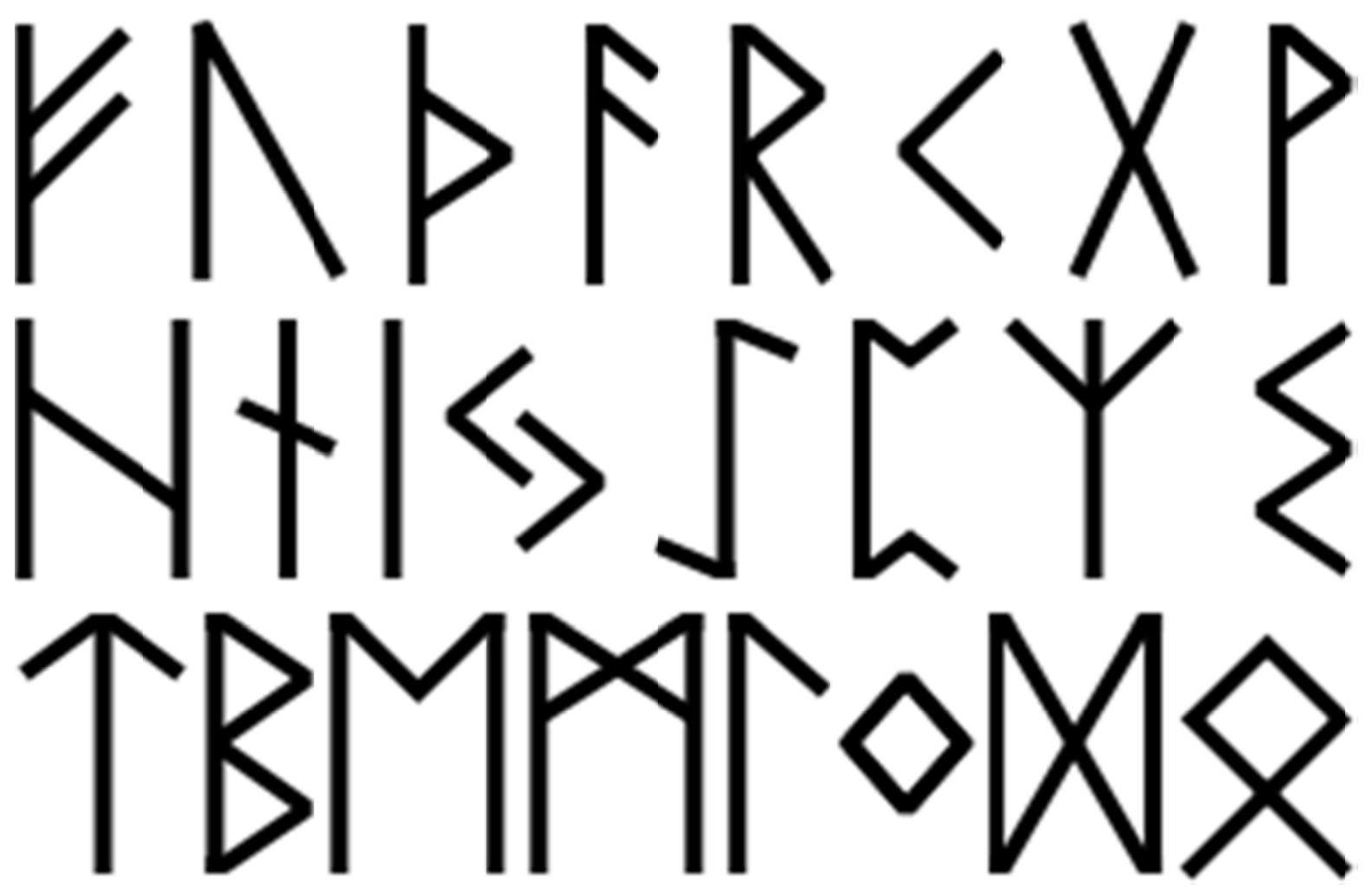

Figure 1

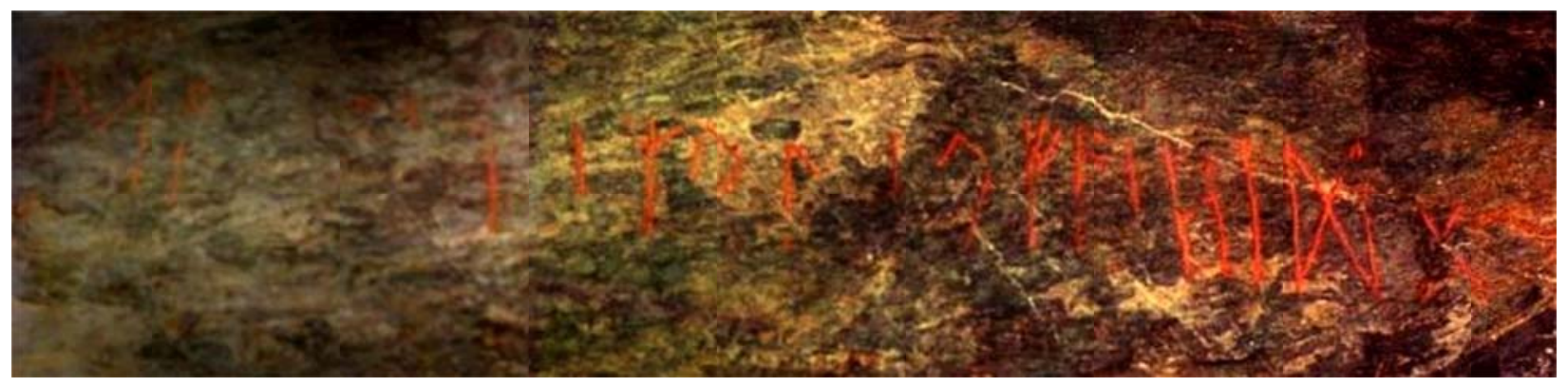

Figure 2 


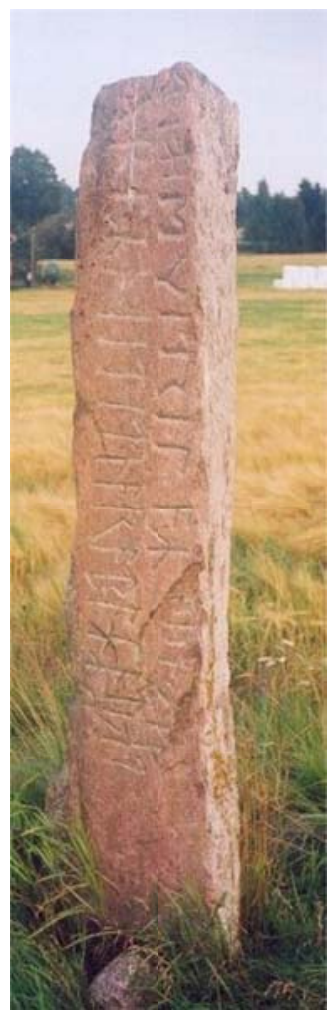

Figure 3

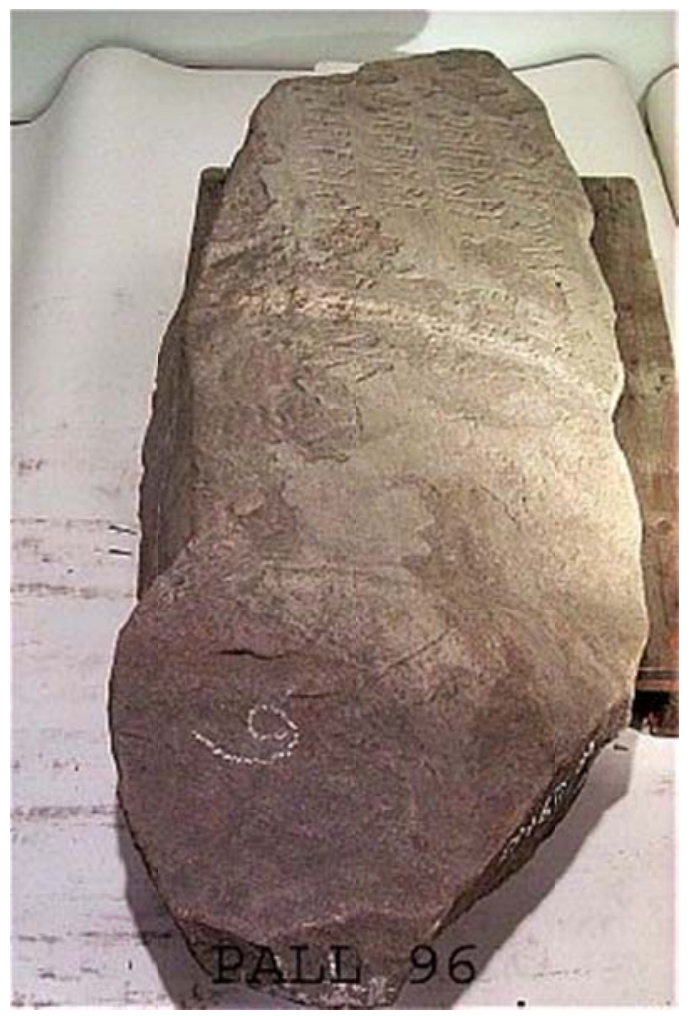

Figure 4 


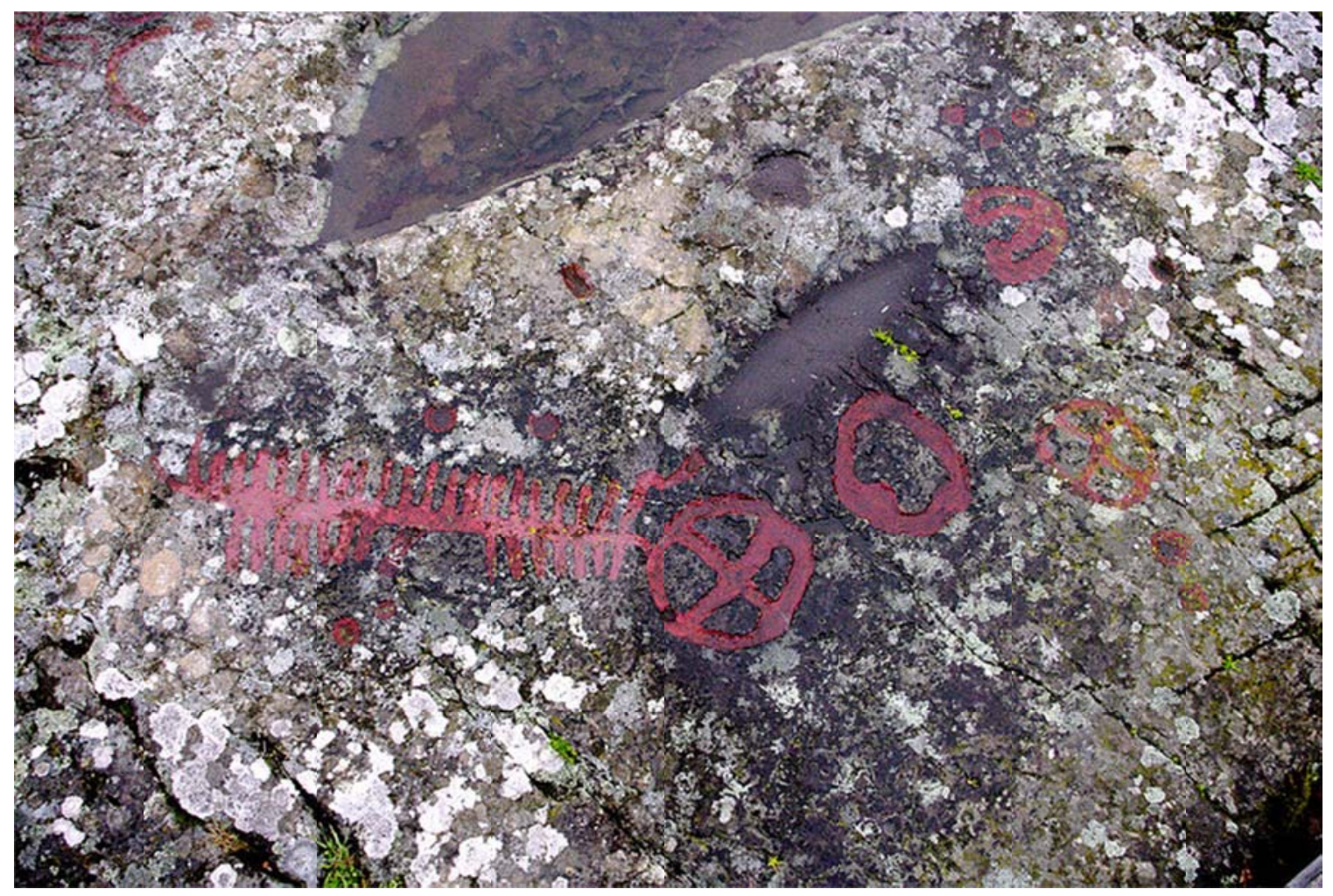

Figure 5

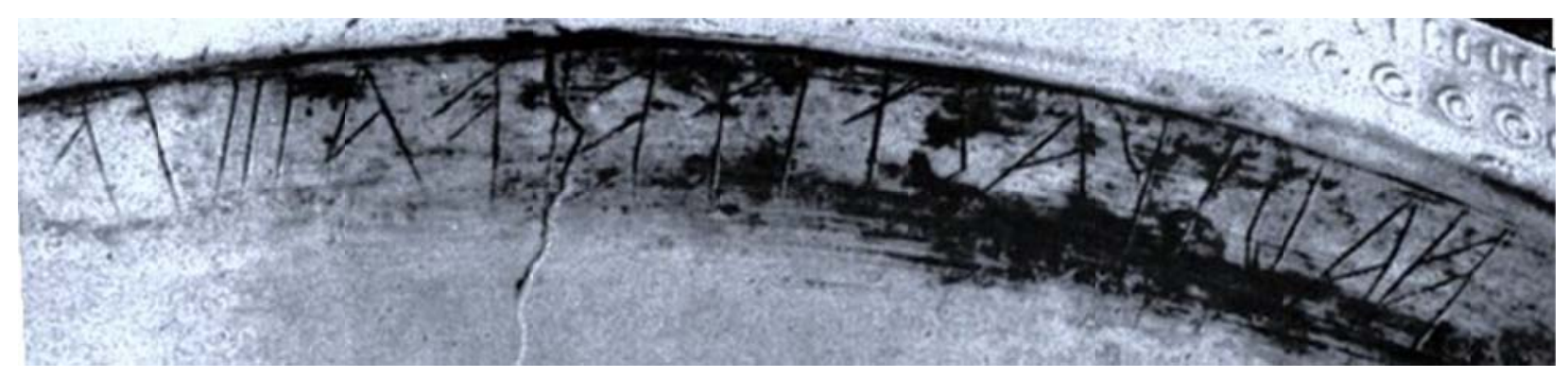

Figure 6 


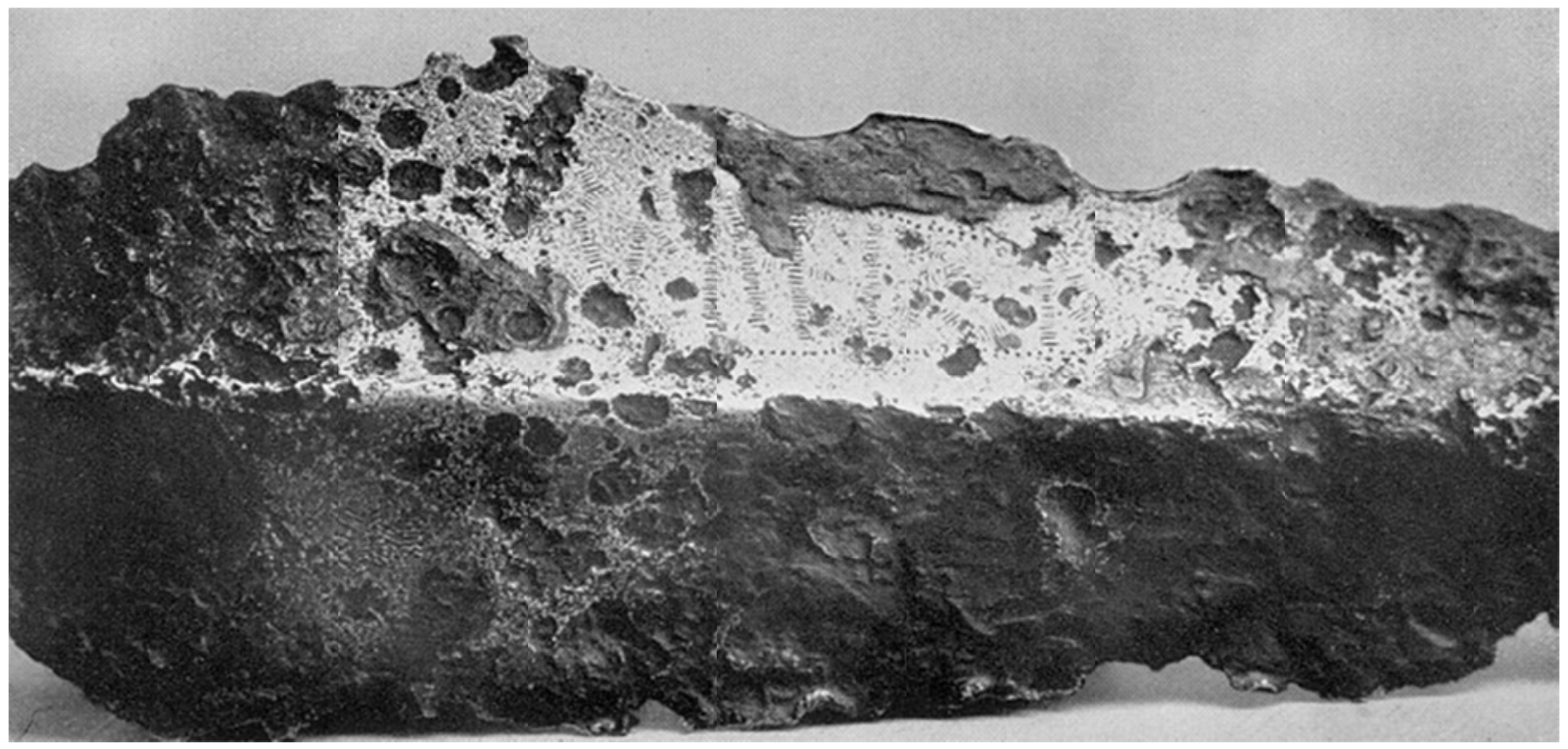

Figure 7

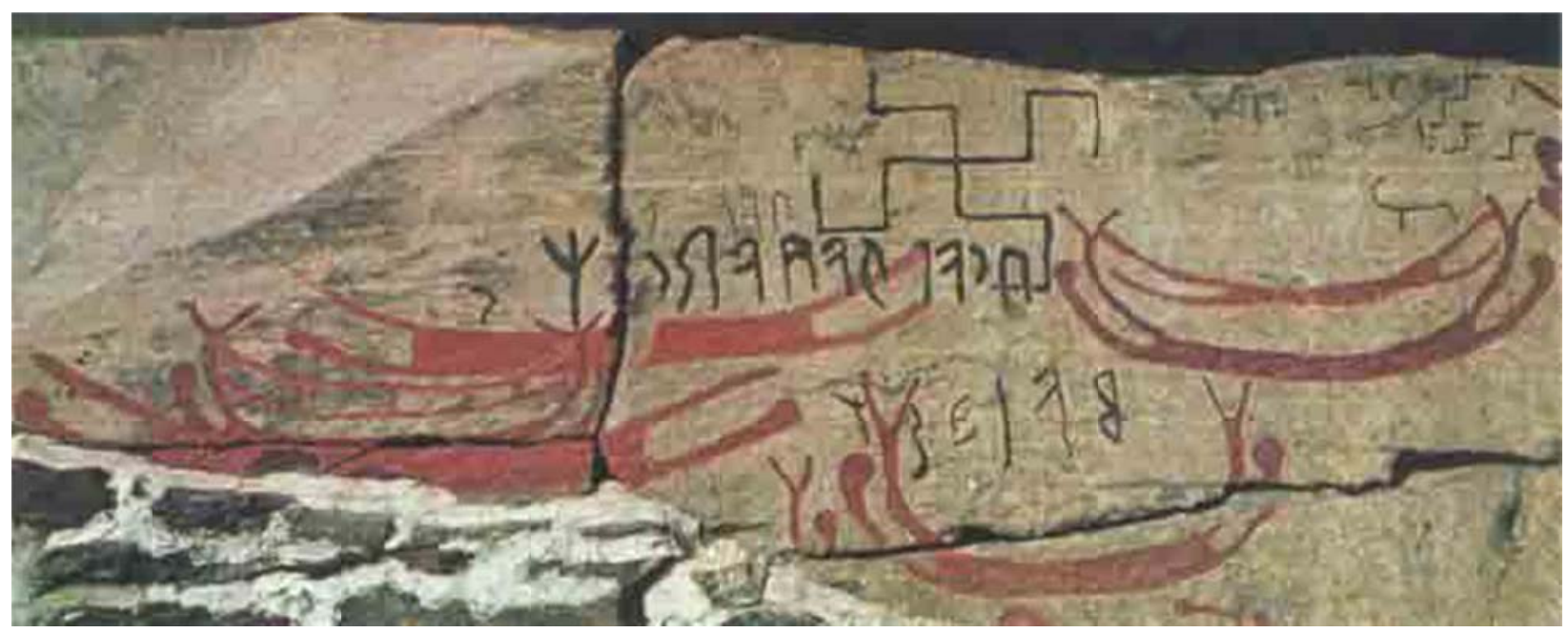

Figure 8 

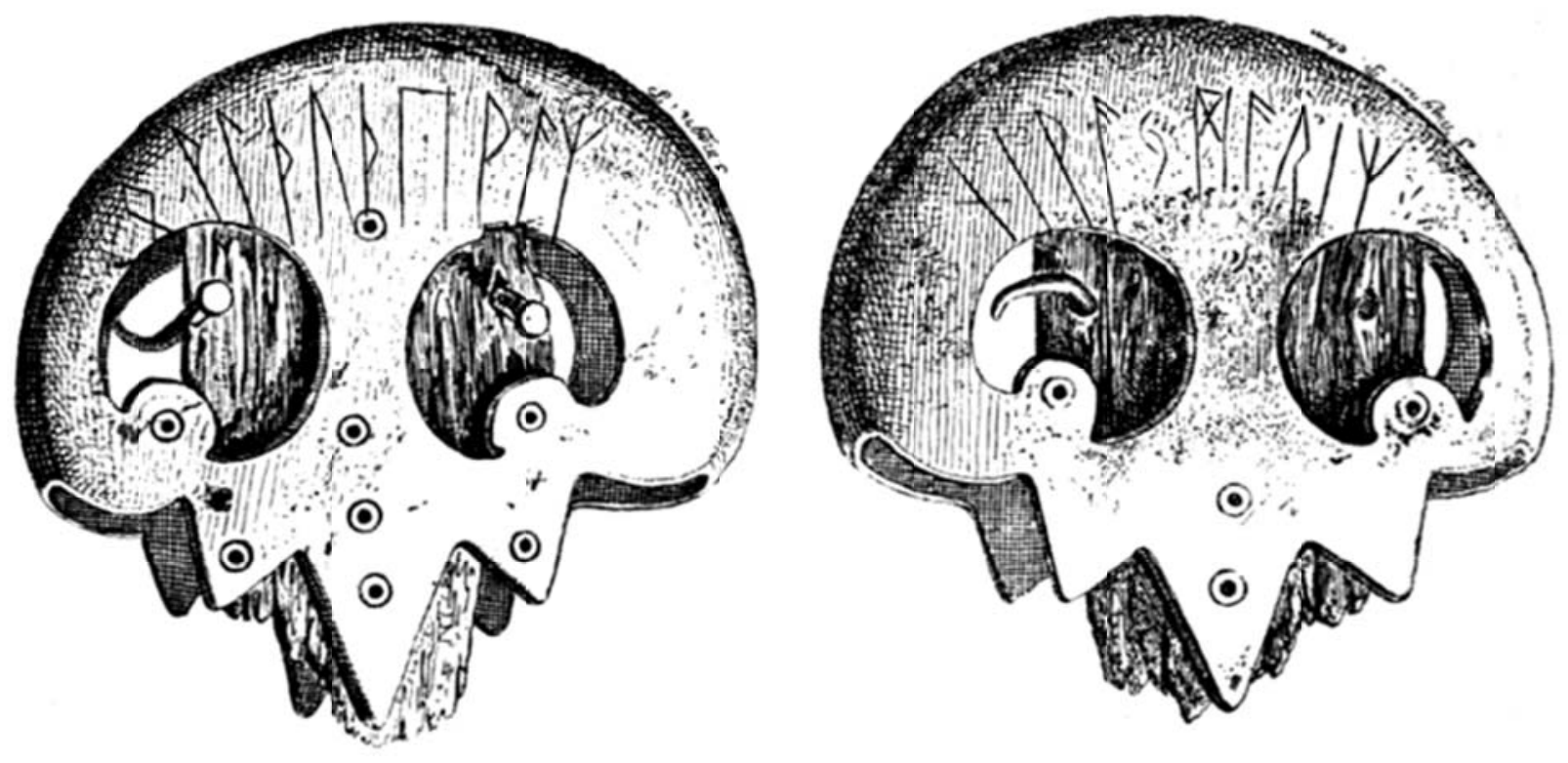

Figure 9

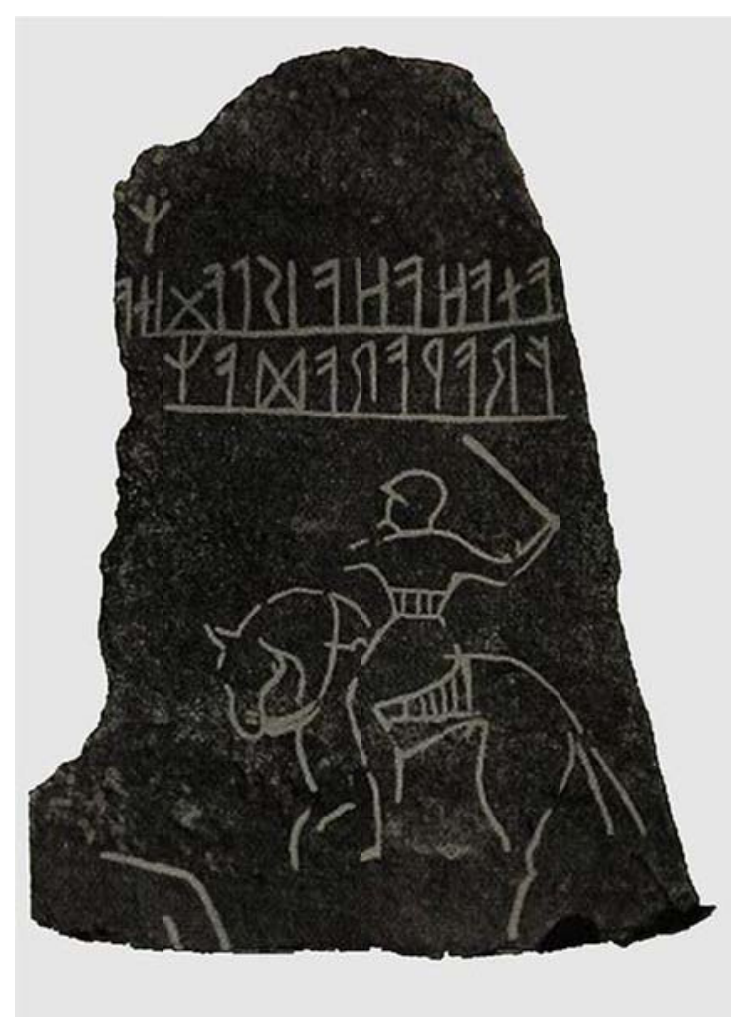

Figure 10 


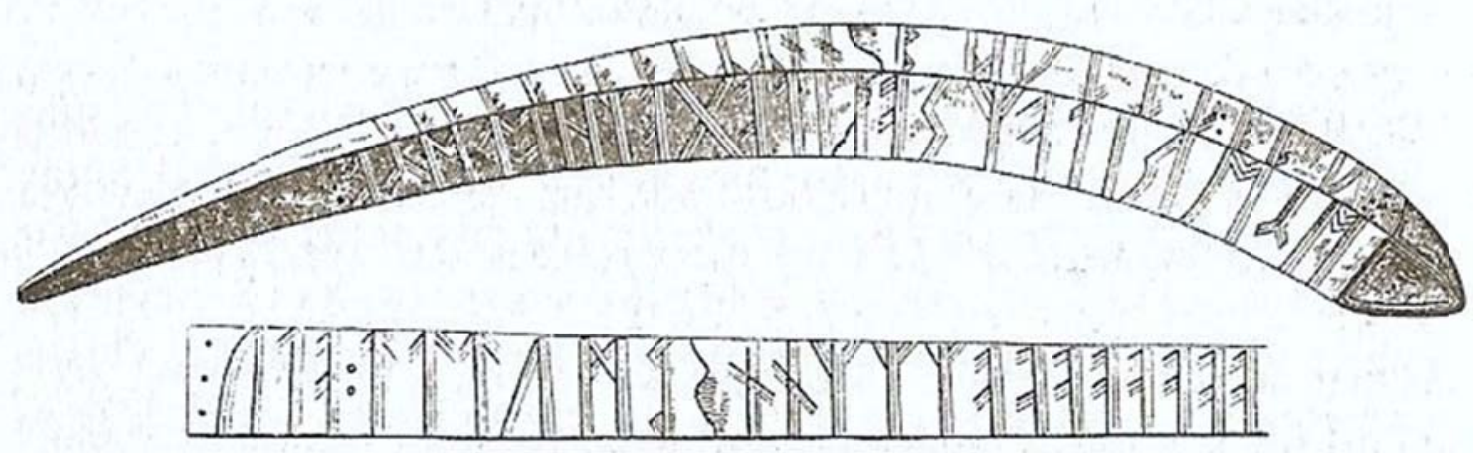

Figure 11

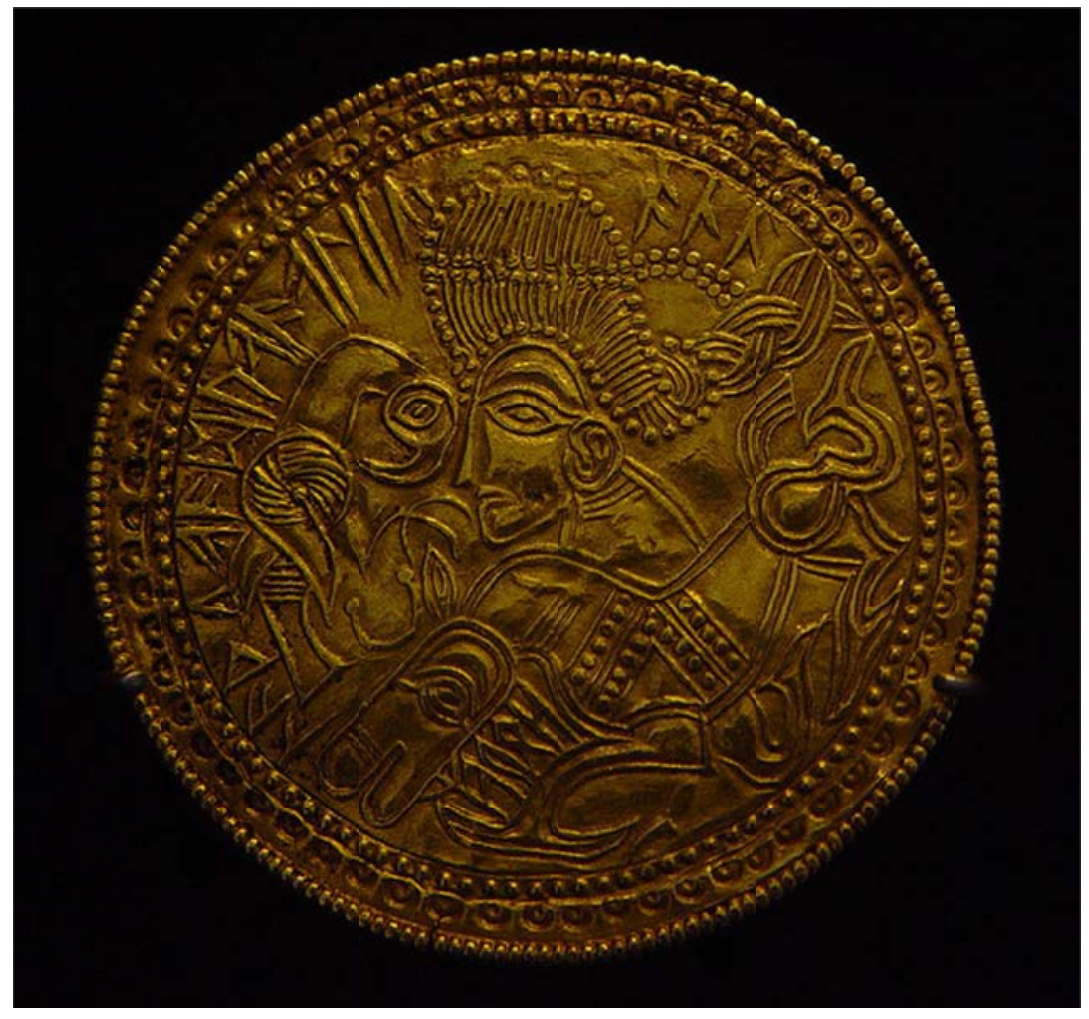

Figure 12 


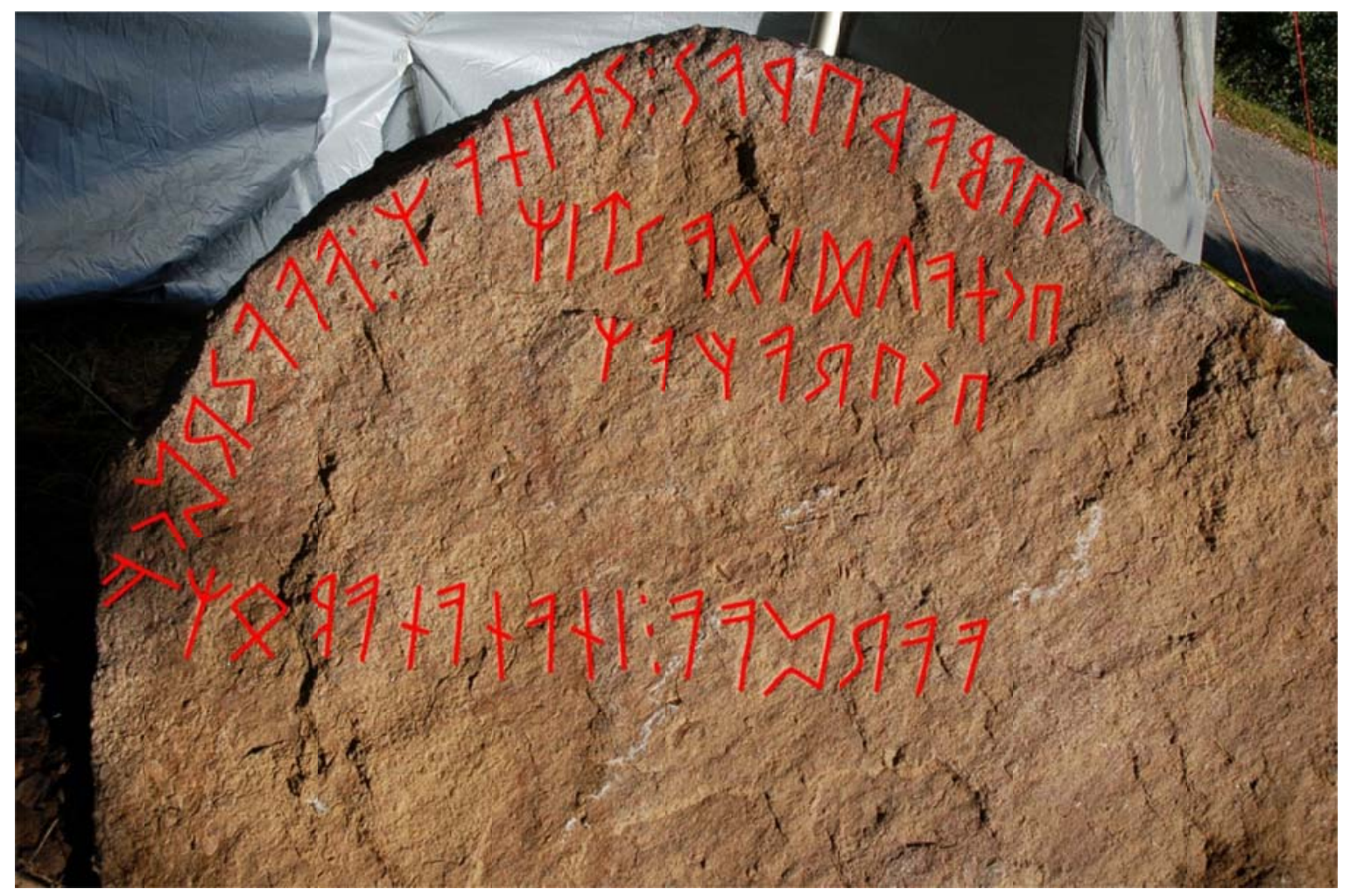

Figure 13

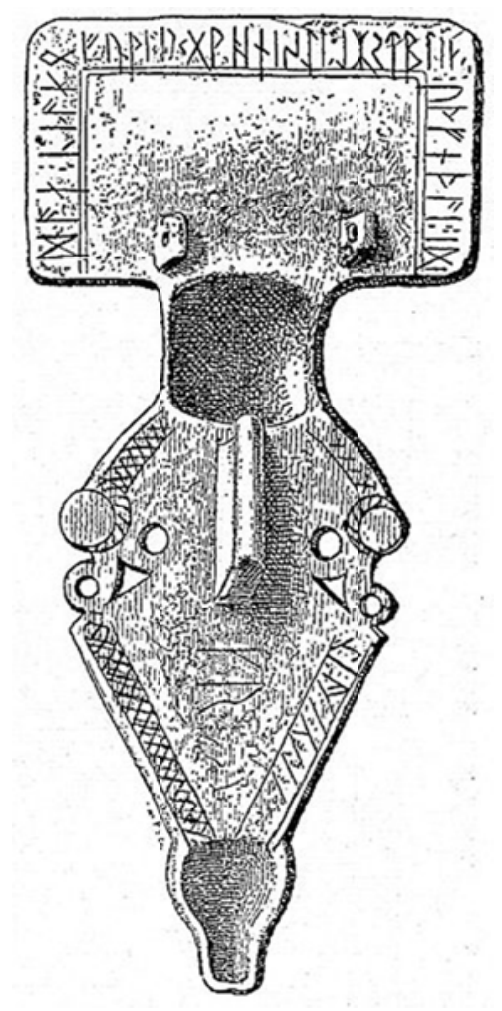

Figure 14 

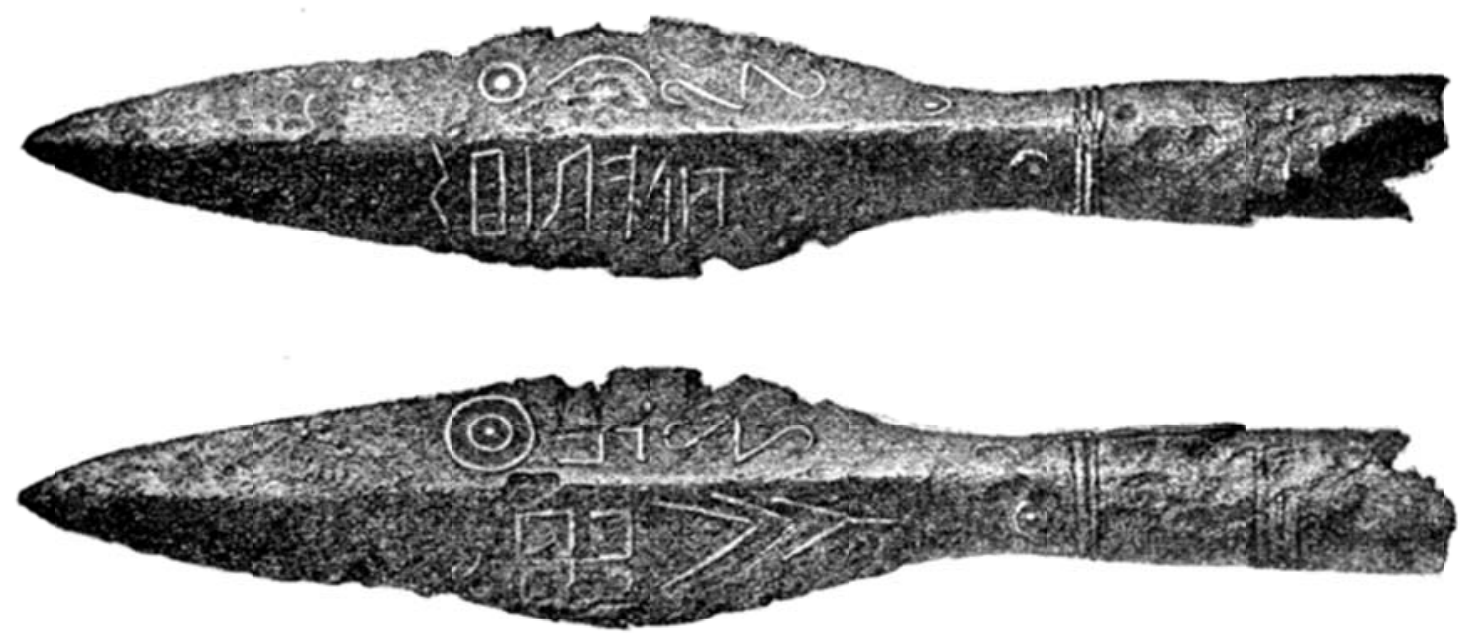

Figure 15

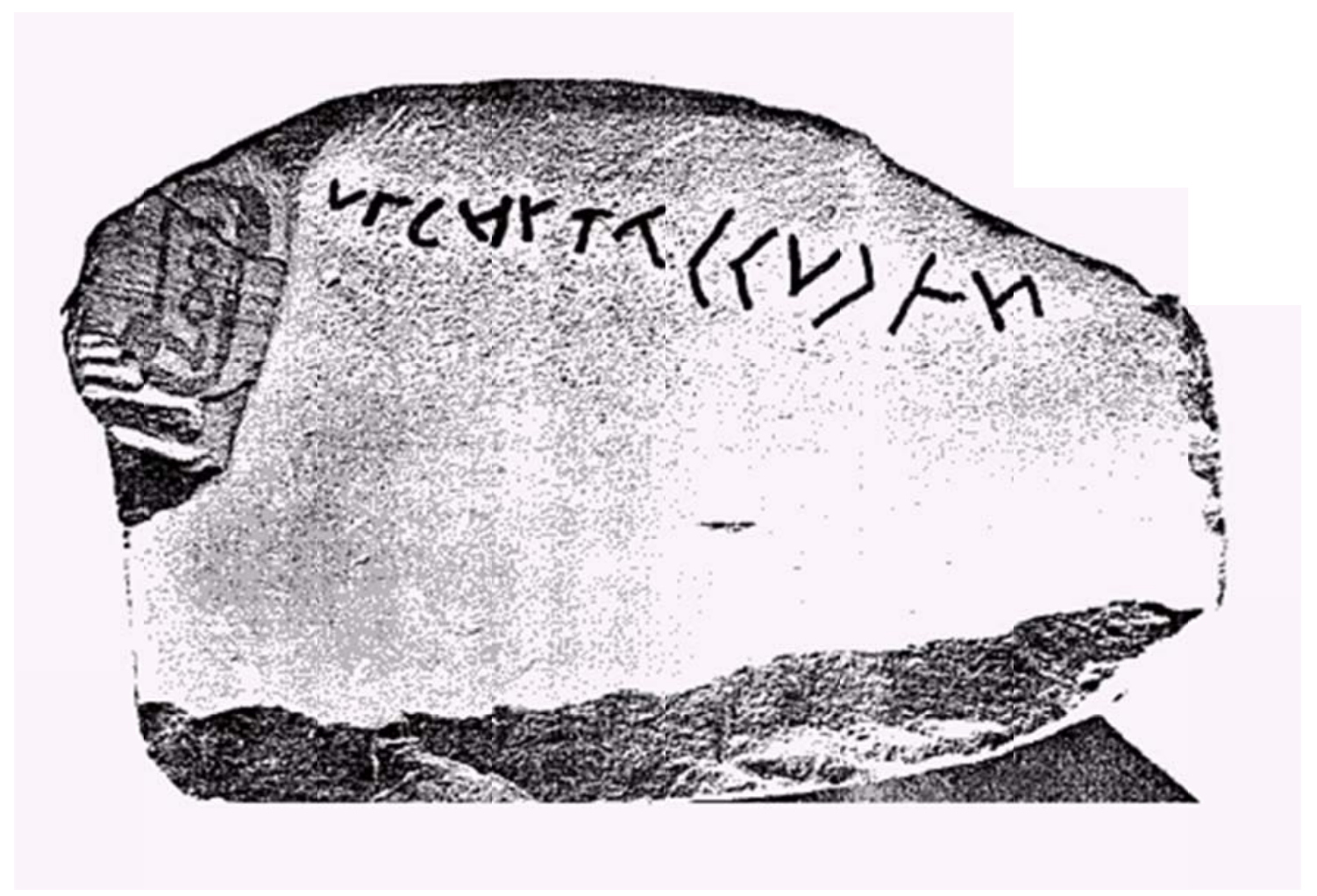

Figure 16 


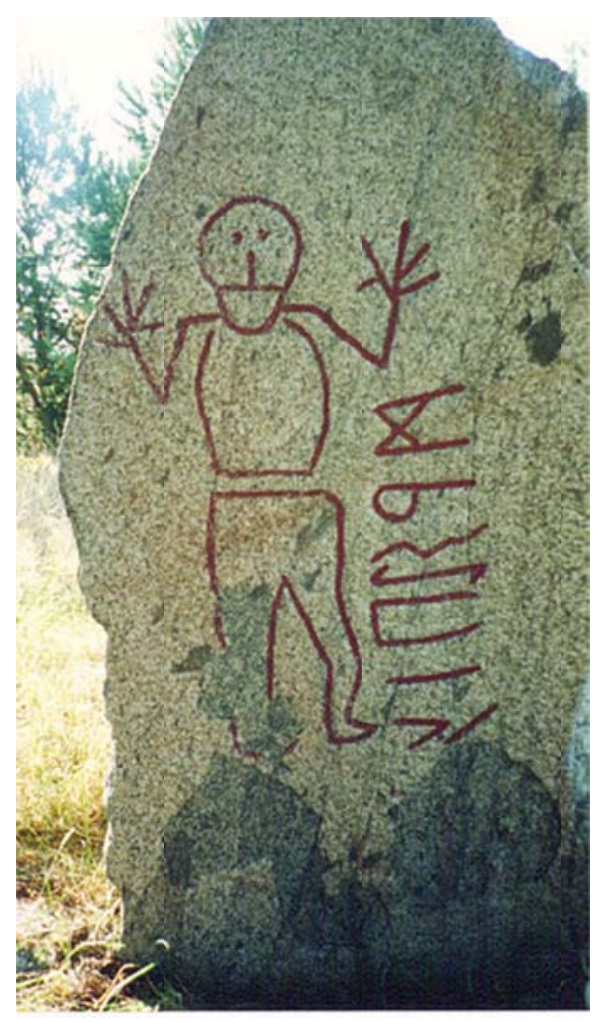

Figure 17

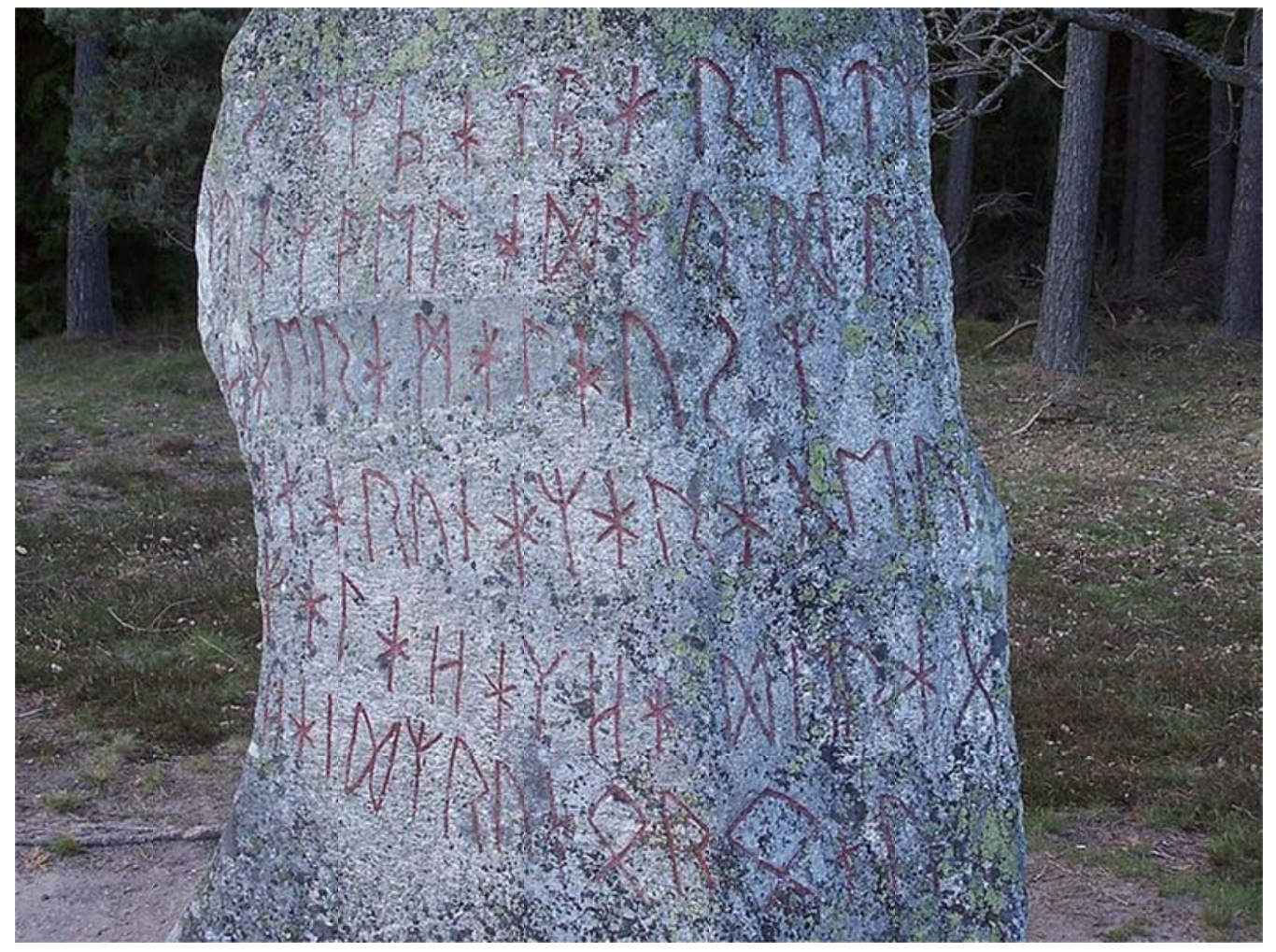

Figure 18 


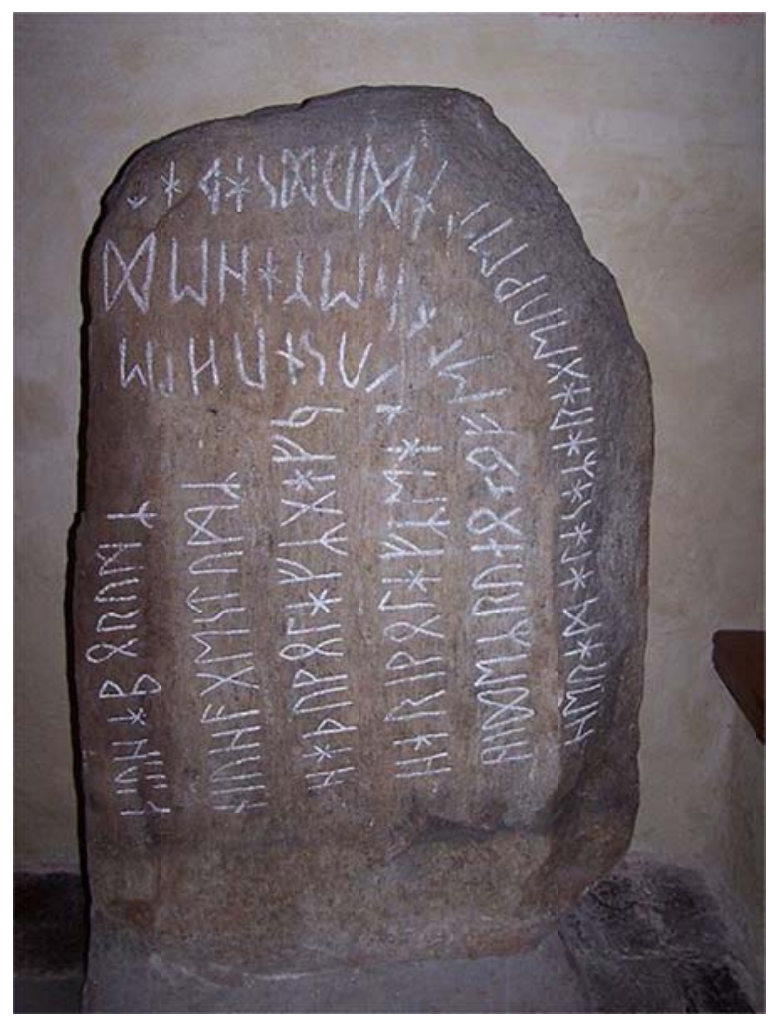

Figure 19

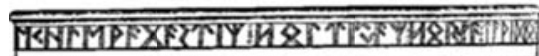
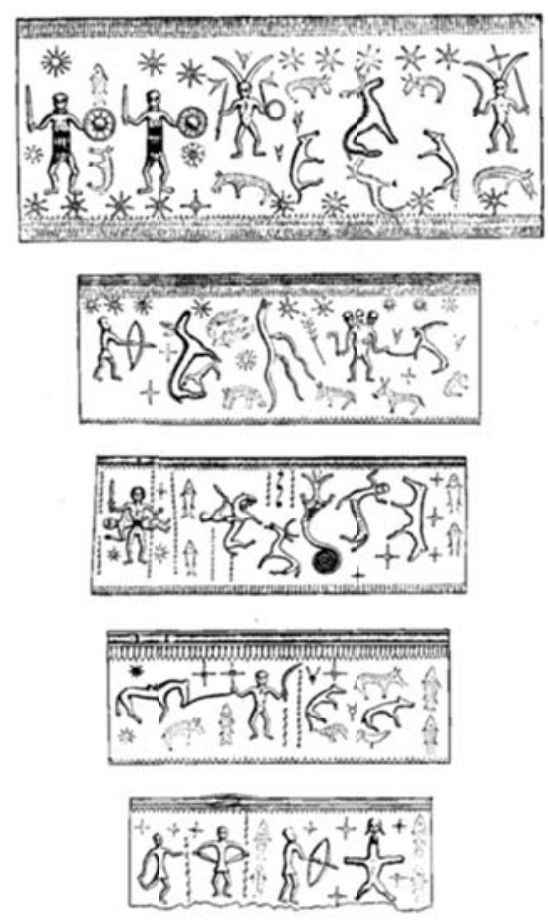

Figure 20 
RUNES: PAST AND PRESENT

Elliott S. Evans

Thesis submitted to the Eberly College of Arts and Sciences at West Virginia University

in partial fulfillment of the requirements for the degree of

Master of Arts

in

Foreign Languages

APPROVAL OF THE EXAMINING COMMITTEE

Cynthia Chalupa, Ph.D.

Deborah Janson, Ph.D.

Date

Johan Seynnaeve, Ph.D., Chair

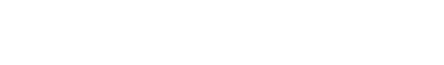

Virginia University Libraries,

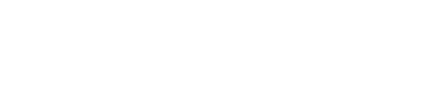

